\title{
Cluster analysis of tropical cyclone tracks in the Southern Hemisphere
}

\author{
Hamish A. Ramsay • Suzana J. Camargo • \\ Daehyun Kim
}

Received: 20 April 2011/Accepted: 14 October 2011/Published online: 30 October 2011

(C) Springer-Verlag 2011

\begin{abstract}
A probabilistic clustering method is used to describe various aspects of tropical cyclone (TC) tracks in the Southern Hemisphere, for the period 1969-2008. A total of 7 clusters are examined: three in the South Indian Ocean, three in the Australian Region, and one in the South Pacific Ocean. Large-scale environmental variables related to TC genesis in each cluster are explored, including sea surface temperature, low-level relative vorticity, deep-layer vertical wind shear, outgoing longwave radiation, El NiñoSouthern Oscillation (ENSO) and the Madden-Julian Oscillation (MJO). Composite maps, constructed 2 days prior to genesis, show some of these to be significant precursors to TC formation-most prominently, westerly wind anomalies equatorward of the main development regions. Clusters are also evaluated with respect to their genesis location, seasonality, mean peak intensity, track duration, landfall location, and intensity at landfall. ENSO is found to play a significant role in modulating annual frequency and mean genesis location in three of the seven clusters (two in the South Indian Ocean and one in the Pacific). The ENSO-modulating effect on genesis frequency is caused primarily by changes in low-level zonal flow between the equator and $10^{\circ} \mathrm{S}$, and associated relative vorticity changes in the main development regions. ENSO
\end{abstract}

\footnotetext{
H. A. Ramsay $(\square)$

Monash Weather and Climate, School of Mathematical Sciences, Monash University, Clayton, Victoria 3800, Australia

e-mail: hamish.ramsay@monash.edu

S. J. Camargo · D. Kim

Lamont-Doherty Earth Observatory, Columbia University,

Palisades, New York, NY, USA

e-mail: suzana@1deo.columbia.edu

D. Kim

e-mail: dkim@1deo.columbia.edu
}

also has a significant effect on mean genesis location in three clusters, with TCs forming further equatorward (poleward) during El Niño (La Niña) in addition to large shifts in mean longitude. The MJO has a strong influence on TC genesis in all clusters, though the amount modulation is found to be sensitive to the definition of the MJO.

Keywords Tropical cyclones · Cluster analysis - ENSO · MJO

\section{Introduction}

Tropical cyclones (TCs) pose a significant threat to communities that lie in their paths, so improving our understanding of large-scale environmental controls on TC formation, track and intensity is of significant importance. Annually, about $30 \%$ of global TCs form in the Southern Hemisphere (Neumann 1993), spanning a large area from the western Indian Ocean to the central Pacific and covering three TC basins: the southwest Indian Ocean (West of $90^{\circ} \mathrm{E}$ ), the Australian Region $\left(90^{\circ} \mathrm{E}-160^{\circ} \mathrm{E}\right)$ and the South Pacific Ocean (East of $160^{\circ} \mathrm{E}$ ). Several recent studies have investigated various characteristics of TCs (e.g., typical track shape, relationship with large-scale circulation, relationship with ENSO, intensity and landfall probability) using cluster analysis in the Northern Hemisphere (e.g., Camargo et al. 2007a, b, 2008; Kossin et al. 2010). However, considerably less attention has been given to studying the behavior of TC tracks in the Southern Hemisphere, particularly over the Indian Ocean.

The goals of the current study are: (1) to investigate the spatial and temporal behavior of Southern Hemisphere TC tracks using a novel clustering technique, and (2) to understand how the large-scale environment modulates the behavior of TCs in each cluster, including common modes 
of natural variability [i.e., El Niño-Southern Oscillation (ENSO) and Madden-Julian Oscillation (MJO)].

The role of large-scale environment in TC formation has been the subject of a large body of research since its inception in the late 1960s (Gray 1968). During the Southern Hemisphere warm season, the Intertropical Convergence Zone (ITCZ), the monsoon trough, and the South Pacific Convergence Zone (SPCZ) all provide breeding grounds for TCs, where necessary conditions for TC genesis come together over narrow spatial zones (e.g., enhanced low-level vorticity and low vertical wind shear through a deep layer).

ENSO has been shown to modulate large-scale fields associated with TC genesis, which in turn affects the annual frequency of TCs for particular regions (see e.g. Camargo et al. 2010). Early studies for the Australian region revealed a significant statistical relationship between ENSO and TC frequency, with more (less) TCs forming near Australia in La Niña (El Niño) conditions (Nicholls 1979, 1984, 1985; Solow and Nichols 1990). Other studies have shown a strong ENSO signal in more localized regions, such as northwest of Australia and the Fiji region (e.g., Broadbridge and Hanstrum 1998; Chand and Walsh 2009; Goebbert and Leslie 2010). In addition to these statistical relationships, a number of studies have explored the ways in which ENSO influences the large-scale fields associated with TC genesis over the Australian region and Southern Hemisphere (e.g., Evans and Allan 1992; Camargo et al. 2007c; Ramsay et al. 2008; Kuleshov et al. 2009, 2010). The South Indian Ocean, in comparison, has received relatively less attention, although several studies have documented geographical shifts in TC activity associated with ENSO, all indicating a general increase (decrease) of activity east (west) of $70^{\circ} \mathrm{E}$ during La Niña (El Niño) events (e.g., Kuleshov and de Hoedt 2003; Ho et al. 2006).

On the intra-seasonal time scale, the MJO has been shown to have a significant impact on Southern Hemisphere TCs (e.g., Leroy and Wheeler 2008). For the South Indian Ocean, Bessafi and Wheeler (2006) found TCs were 2.6 times more likely to form in the active phase of the MJO compared with its inactive phase. Hall et al. (2001) showed that the MJO influence on TC formation is even more pronounced over the Australian region, particularly to the northwest of Australia between about $90^{\circ}$ and $120^{\circ} \mathrm{E}$ where large differences in TC genesis rate were linked with active and inactive phases. More recently, Chand and Walsh (2010) found a strong modulation of TC genesis by the MJO in the Fiji region $\left(5^{\circ}-\right.$ $\left.15^{\circ} \mathrm{S}, 170^{\circ} \mathrm{E}-170^{\circ} \mathrm{W}\right)$. Significantly more TCs were found to form when the active MJO phase was localized over the western North Pacific and western Hemisphere, and fewer when the active region was localized over the Indian Ocean, based on the Wheeler-Hendon MJO Index (Wheeler and Hendon 2004). Camargo et al. (2009) examined large-scale variables related to the modulation of TC activity by the MJO globally, with the strongest MJO modulation of TCs occurring in the Southern Hemisphere.

The clustering technique proposed by Gaffney (2004), as used herein, has yet to be applied to TCs in the South Indian Ocean and Australian region, though it was recently used by Chand and Walsh (2009) to explore the characteristics of TC tracks in Fiji region. They identified three distinct clusters, with two of the three being significantly modulated by ENSO whereby El Niño (La Niña) conditions led to more (less) TCs, in addition to a northeastward shift in mean genesis location. In the present study, we extend the analysis of Chand and Walsh (2009), as well as other related papers concerning the Northern Hemisphere (e.g., Camargo et al. 2007a, b, 2008; Kossin et al. 2010), to TC tracks over the entire Southern Hemisphere.

The outline of this paper is as follows. Section 2 provides a description of the various data sets and definitions. The data analysis methods and statistical techniques are discussed in Sect. 3. Our main findings are presented in Sect. 4, and summarized in Sect. 5.

\section{Data and definitions}

Tropical cyclone data for the period July 1969-June 2008 were obtained from the International Best Track Archive for Climate Stewardship v02r01 (IBTrACS) (Knapp et al. 2010) maintained by National Climate Data Center (NCDC). IBTrACS is a global dataset that combines best track data from various Regional Specialized Meteorological Centers (RMSCs) and Tropical Cyclone Warning Centers (TCWCs) around world. The use of IBTrACS for the Southern Hemisphere is particularly appealing since the best track data are maintained by several RMSCs and TCWCs; RSMC La Reunion, RMSC Nadi, and the TCWCs of Perth, Darwin, Brisbane and Wellington. Data from the Joint Typhoon Warning Center (JTWC) are also included. Though the IBTrACS data starts in 1848 for the Southern Hemisphere, we use data only from 1969 owing to questionable data quality during the pre-satellite era. The data set also includes tropical depressions, though they make up only a small percentage of the total number of systems. For TC intensity analysis we use data starting from 1981/1982 season. The TC intensity data in the Southern Hemisphere prior to the early 1980s have been shown to be unreliable due to both an incomplete record and a tendency to underestimate intensity of systems (e.g., Nicholls et al. 1998; Harper et al. 2008; Kuleshov et al. 2008). Here, TC genesis is taken simply as the first occurrence of an individual system in the IBTrACS dataset.

Weekly sea surface temperature (SST) data were obtained from the NOAA Optimum Interpolation SST data set (Reynolds et al. 2002) for 1981-2008. The data set has 
a spatial resolution of one degree. Daily Outgoing Longwave Radiation (OLR) data were extracted from the NOAA Interpolated OLR data set (Liebmann and Smith 1996) starting from 1974 with a spatial resolution of $2.5^{\circ}$. Daily atmospheric variables, including zonal and meridional winds at 850 and $200 \mathrm{hPa}$, relative humidity at $600 \mathrm{hPa}$, sea-level pressure, and $500-\mathrm{hPa}$ geopotential height, were all obtained from the NCEP-NCAR Reanalysis 1 data set (Kalnay et al. 1996).

ENSO phase was defined using 3-monthly Niño 3.4 SST index (Barnston et al. 1997) obtained from the Climate Prediction Center (http://www.cpc.noaa.gov/data/indices/ sstoi.indices). First, the 3-monthly January-March Niño 3.4 anomalies were sorted from lowest to highest values. Using the same approach as Goddard and Dilley (2005) and Camargo et al. (2007b), El Niño (La Niña) seasons were defined as the years corresponding to the top (bottom) quartile of the sorted values, and the Neutral seasons as the middle 50\%. These separation criteria resulted in $10 \mathrm{El} \mathrm{Niño}$ seasons (1972/1973, 1976/1977, 1982/1983, 1986/1987, 1987/1988, 1991/1992, 1994/1995, 1997/1998, 2002/2003, 2004/2005), 10 La Niña seasons (1970/1971, 1973/1974, 1975/1976, 1984/1985, 1988/1989, 1995/1996, 1998/1999, 1999/2000, 2005/2006, 2007/2008), and 19 Neutral seasons for the period July 1969-June 2008.

The Wheeler-Hendon MJO Index (Wheeler and Hendon 2004) was used to stratify TC genesis by the eight phases of the MJO. The original MJO index is available only back to 1974 , owing to the time period of available OLR data. Here, as in Chand and Walsh (2010), we use the original MJO index from 1974 (based on OLR and wind data), and from 1969 to 1974 we use a similar but modified MJO index based on wind data only (provided by M. Wheeler, personal communication, 2010). To investigate possible local influence of MJO-related convection on TC genesis, MJO-filtered OLR anomaly data are constructed by isolating signals with MJO's spatial (wavenumber 1-5) and temporal (period 30-96 days) scales (Wheeler and Kiladis 1999).

Finally, to analyze landfall characteristics of TCs a highresolution land-sea mask was necessary. We use a veryhigh resolution 1-km land-sea mask developed at the Group for High Resolution Sea Surface Temperature (available at https://www.ghrsst.org/GHRSST-PP-NAVOLand-and-sea-Mask.html). In addition to its $1-\mathrm{km}$ resolution, the data also contain information on distance from ocean to land up to $50 \mathrm{~km}$ away from coastlines. This extra information is particularly useful for examining the impacts from TCs whose centers remain over water, as TCs that approach land can have major impacts on coastal communities without actually making landfall.

\section{Methods}

\subsection{Cluster technique}

The clustering method proposed by Gaffney (2004) is used to separate the TC tracks into separate groups or clusters, such that the most similar tracks are in the same group. The characteristics of the tracks used to decide which are most similar include where they initiate, the location of maximum wind speed, and the shape of the trajectories, amongst several other factors. Other cluster techniques have been applied to study TC tracks, such as fuzzy (Harr and Elsberry 1995; Kim et al. 2011), K-means (Elsner 2003; Elsner and Liu 2003) and mass moments (Nakamura et al. 2009) methods.

The only information about the TCs used in the current cluster analysis is their tracks: longitude and latitude. This cluster analysis can be applied to any kind of trajectories, as discussed in Gaffney (2004). A detailed description of the technique and its application to extratropical North Atlantic cyclones is given in Gaffney et al. (2007). Examples of application of this technique to TC tracks are given in Camargo et al. (2007a, b) (western North Pacific), Camargo et al. (2008) (eastern North Pacific), Kossin et al. (2010) (North Atlantic) and Chand and Walsh (2009) (Fiji region).

The technique builds a mixture of polynomial regression functions (curves), in order to fit the geographical shape of the trajectories. The idea is that this mixture of underlying functions could have generated the observed TC tracks. In this case we used quadratic functions, though higher order polynomial functions could have been used. The method is an extension of the standard finite mixture model, which enables highly non-Gaussian probability functions. The model is fit to the data maximizing the likelihood of the parameters.

One of the advantages of this cluster technique over others is its ability to accommodate trajectories of different lengths, in contrast with K-means method for example. Each TC is assumed to be generated by one of the clusters, with each cluster having a different regression model with its own shape parameters.

The clustering technique here was applied to 1,329 TC trajectories from the IBTrACS data set for the period July 1969-June 2008. The choice of the number of clusters is not uniquely determined. As in other studies (Camargo et al. 2007a, 2008; Kossin et al. 2010), the range of possible choices for the number of clusters is first done using the in-sample log-likelihood, basically a goodness of fit metric for probabilistic methods. As in Camargo et al. (2008), we also investigated to what extent tracks shifted 
from one cluster to another as the number of clusters (K) was increased. In addition, careful attention was paid to which clusters stayed intact and which split into two or more clusters, as well as differences in shape and position of the regression trajectories, as $\mathrm{K}$ was increased.

Inspection of the internal log-likelihood and withincluster error plots suggested an optimal number of clusters in the range of 6-10, with diminishing returns beyond 10 clusters. For $\mathrm{K}=6-10$, we examined the stability of the clustering solutions by resampling the regression model 100 times and looking at the resulting spread of regression coefficients. As $\mathrm{K}$ increased, the general tendency was for the solution to become more statistically unstable, as the tracks switched from one cluster to another. This was particularly notable in the region north of Australia and eastward to the Coral Sea, where the TC tracks tend to be more erratic, imposing an inherent physical limit on finding the "best fit" there. For each choice of K, we also used the relation of number of TCs per cluster and ENSO: the number of TCs in each cluster per year was correlated with the time series of Jan-Mar Niño 3.4 SST. The K with the least spread in regression coefficients, as well as maximum correlation with ENSO (see Table 1), was $\mathrm{K}=7$. In the next section we describe the spatial distribution and seasonality of these clusters.

\subsection{Composites of large-scale fields}

Composites of large-scale fields were constructed using daily anomalies averaged over all days corresponding to TC genesis, as well as 1, 2 and 3 days prior to genesis. A common issue with any study dealing with composite fields associated with TCs is the possible contamination of the environmental field by the TC circulation itself. In an effort to avoid this issue, we consider only composites 2 days prior to genesis. Having this 2-day window also means that the fields considered can be viewed as possible precursors to TC genesis, with potential application to short-term forecasting.

Kernel Density Estimation (KDE; Bowman and Azzalini 1997, pp. 52-53) was used to describe the scatter of TC genesis points for each cluster. $\mathrm{KDE}$ is a nonparametric statistical technique whereby a density function is used to produce a smooth, continuous estimate of the true density of an empirical distribution. As in Ramsay et al. (2008), we choose the 25,50 and $75 \% \mathrm{KDE}$ contours to represent the spatial distribution of TC genesis points.

\subsection{Statistical significance}

Statistical significance of composite fields was determined using a moving block bootstrap test (Künsch 1989; Liu and Singh 1992), with fixed block lengths of $N / 10$. The null hypothesis is that the composite anomalies are not significantly different from zero. Further significance tests were conducted using background climatologies based on days in which no TCs were present, yet which were constrained to have the same seasonal cycle and same number of days as the TC composites. The significance of the anomalies using this background climatology was found to be very similar to the significance based on the null hypothesis described above (not shown). For the clusters associated with ENSO, we test the null hypothesis that the difference between the two phases (El Niño minus La Niña) is not significantly different from zero.

Pearson's $\chi^{2}$ test was used to test significance associated with categorical data, such as ENSO phase. For the MJO analysis, a Monte Carlo approach was used whereby random MJO phases were assigned to each cluster 1,000 times.

\section{Results}

\subsection{Spatial distribution and seasonality}

The individual TC tracks of clusters 1-7, separated by cluster, are shown in Fig. 1, while Fig. 2 shows all TC tracks for the Southern Hemisphere, with the regression curves for each cluster overlaid. It is clear from Fig. 2 that TCs which form west of about $140^{\circ} \mathrm{E}$ (clusters 1-5) generally have westward trajectories, whereas those east of $140^{\circ} \mathrm{E}$ (clusters $6-7$ ) are characterized by eastward movement. The eastward movement in clusters 6 and 7 is due to a mean easterly mid-level steering flow in the South Pacific region (south of about $18^{\circ} \mathrm{S}$ ), in agreement with previous studies (e.g., Holland 1984; Sinclair 2002). The geographical domain of cluster 6 has been shown to be a

Table 1 Correlations between the time series of Jan-Mar Niño 3.4 and Niño 4 SST, and the annual number of TCs in each cluster

\begin{tabular}{llllllll}
\hline & C1 & C2 & C3 & C4 & C5 & C6 & C7 \\
\hline Nino 3.4 & 0.08 & -0.05 & $-\mathbf{0 . 5 8}$ & $-\mathbf{0 . 5 8}$ & -0.04 & -0.13 & $\mathbf{0 . 5 3}$ \\
$95 \%$ CI & $-0.198,0.353$ & $-0.390,0.287$ & $-0.771,-0.383$ & $-0.729,-0.430$ & $-0.417,0.324$ & $-0.460,0.184$ & $0.287,0.810$ \\
Nino 4 & 0.06 & 0.03 & $-\mathbf{0 . 4 8}$ & $-\mathbf{0 . 5 8}$ & -0.02 & -0.18 & $\mathbf{0 . 3 6}$ \\
$95 \%$ CI & $-0.235,0.357$ & $-0.246,0.299$ & $-0.732,-0.230$ & $-0.724,-0.428$ & $-0.290,0.247$ & $-0.524,0.152$ & $0.151,0.575$
\end{tabular}

Significant correlations are indicated in bold. The $95 \%$ confidence intervals are also shown following a bootstrap test with 1,000 replications 

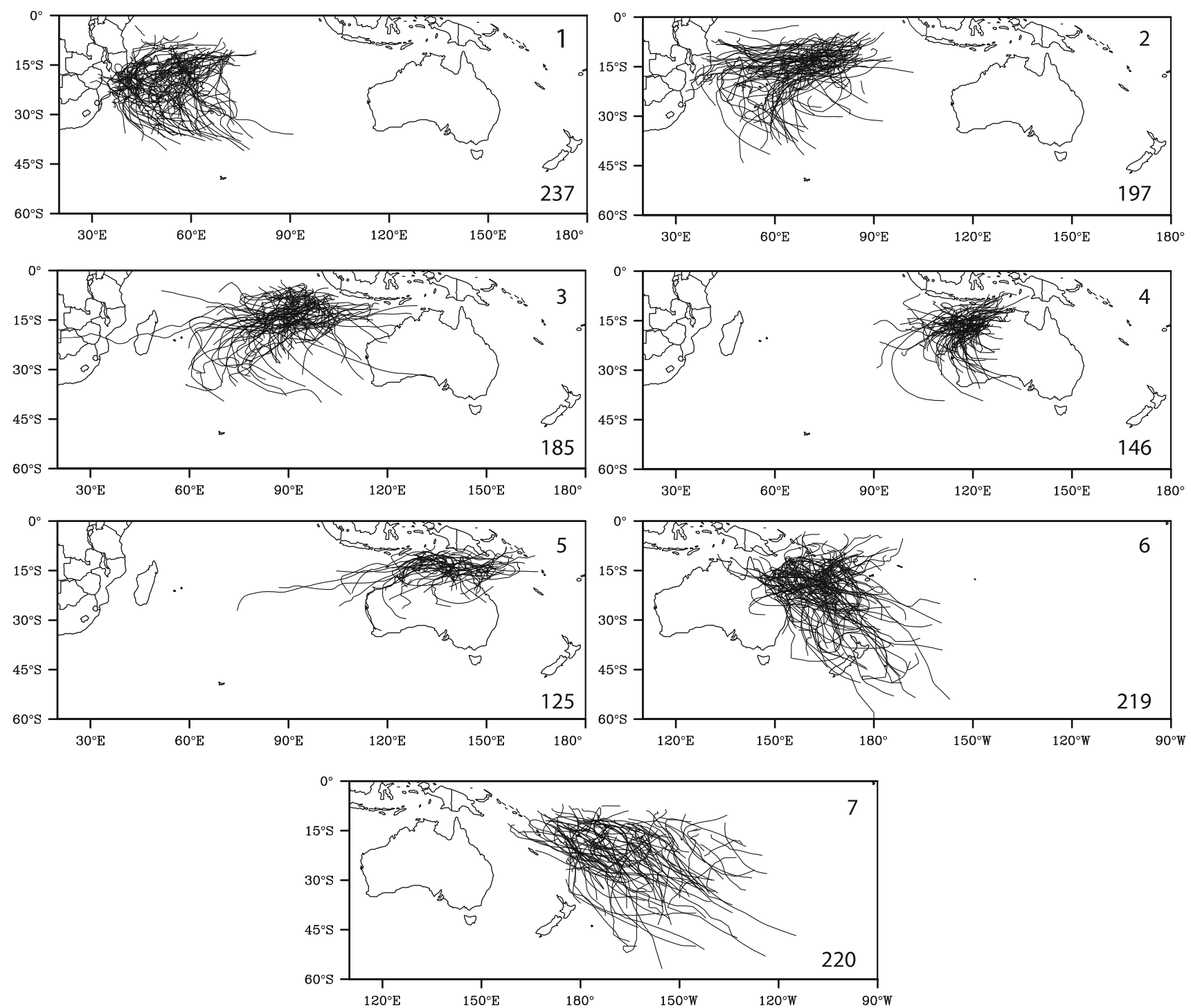

Fig. 1 TC tracks that make up each of the 7 clusters. The cluster number is shown in the top-right of each panel, and the number of TCs in the bottom-right

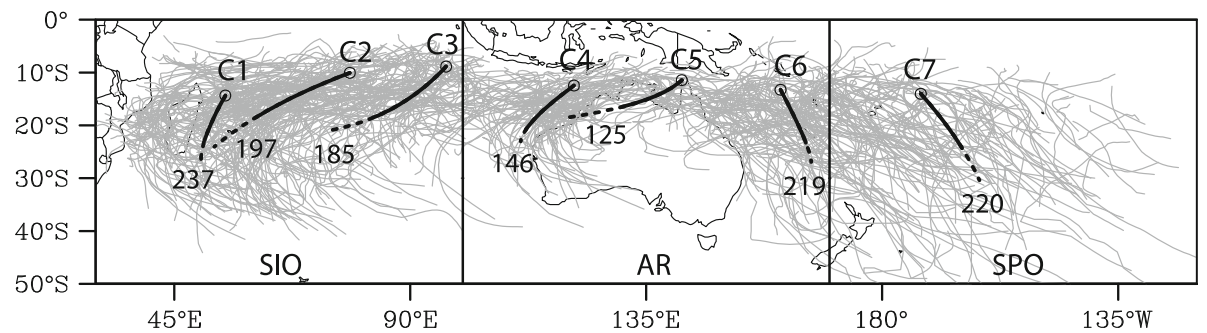

Fig. 2 Regression trajectories (bold curves) for the 7 clusters over the Southern Hemisphere. The solid (dashed) parts indicate the mean (mean plus one standard deviation) TC lifetime for each cluster. The

favorable region for extratropical transition, (e.g., Sinclair 2002; Pezza and Simmonds 2008), consistent with a significant fraction of TCs that move poleward of $35^{\circ} \mathrm{S}$ there (Fig. 1). A common trait of all regression curves in the number of TCs is shown below the regression trajectories. Individual TC tracks are plotted in gray. The three sub-basins-SIO (west of $\left.100^{\circ} \mathrm{E}\right), \mathrm{AR}\left(100^{\circ} \mathrm{E}-170^{\circ} \mathrm{E}\right)$ and $\mathrm{SPO}$ (east of $\left.170^{\circ} \mathrm{E}\right)$ - are also shown

Southern Hemisphere is the general lack of recurvature as TCs track poleward, based on truncation using mean TC lifetime plus one standard deviation (Fig. 2). While some individual tracks show strong recurvature, as seen 


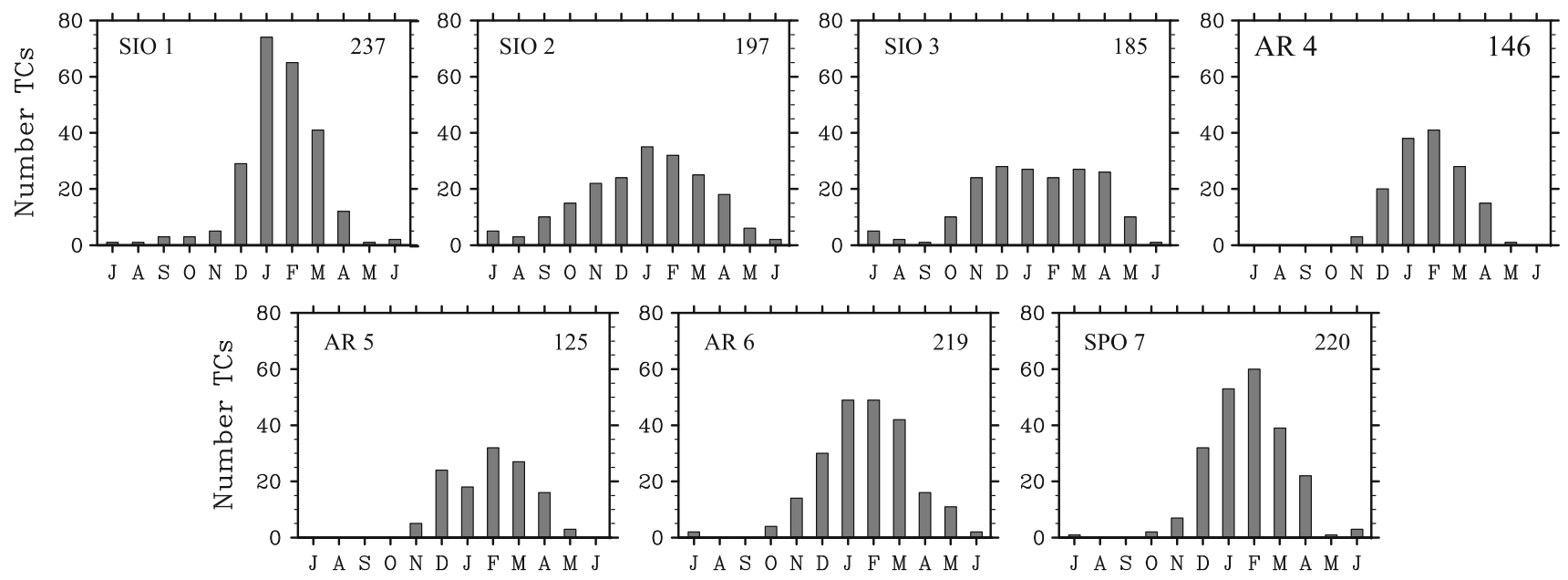

Fig. 3 The frequency of TCs by month for each cluster. The sub-basin and cluster number is shown in the top-left, and the total number of TCs top-right

particularly in cluster 1 , they represent a smaller fraction of the total TCs in each cluster. This is in contrast to the presence of clusters with a typical recurving regression trajectory in the western North Pacific and North Atlantic (Camargo et al. 2007a; Kossin et al. 2010), but similar to the eastern North Pacific, where the regression trajectories tend to be also relatively straight (Camargo et al. 2008).

Given the large longitudinal expanse of the Southern Hemisphere TC region, it is useful as a point of reference to separate the domain into three sub-regions; (1) South Indian Ocean, west of $100^{\circ} \mathrm{E}$ (hereafter, SIO), (2) Australian Region, from $100^{\circ} \mathrm{E}$ to $170^{\circ} \mathrm{E}$ (hereafter AR), and (3) South Pacific Ocean, east of $170^{\circ} \mathrm{E}$ (hereafter, SPO). Note that the definition of the Australian Region here encompasses an area slightly eastward of the official region of responsibility used by the Australian Bureau of Meteorology $\left(90^{\circ} \mathrm{E}\right.$ to $\left.160^{\circ} \mathrm{E}\right)$. We use $100^{\circ} \mathrm{E}$ longitude to separate the AR from the SIO because this longitude occurs at a minimum in the spatial density of TC genesis and tracks.

Using the three sub-regions defined above, there are three clusters in the SIO (clusters $1-3,46 \%$ of total TCs), three in the AR (clusters 4-6, 37\% of total TCs), and 1 in the SPO (clusters 7, 17\% of total TCs). Cluster 1 accounts for $18 \%$ of all Southern Hemisphere TCs-the largest of the 7 clusters, situated in the western SIO-while clusters 4 and 5, over the AR, are the two smallest with $146(11 \%)$ and $125(9 \%)$ TCs, respectively.

More than $90 \%$ of all TCs form in the months November to April, the official TC season designated by the Australian Bureau of Meteorology, with peaks in January (294 TCs, 22\%) and February (303 TCs, 23\%). Turning to the individual clusters, there are several distinct differences in their seasonal cycles (Fig. 3). Most notably, Clusters 2 and 3 in the central SIO have much flatter seasonal cycles, with a tendency for more TCs to form outside the core November-April months (Fig. 3). This behavior is most likely the result of the mean position and width of the ITCZ in the SIO, including the wellknown double ITCZ during austral winter and spring (e.g., Waliser and Gautier 1993; Philander et al. 1996). The time-averaged annual mean zonal wind is westerly at the equatorial SIO and latitudes just south, resulting in favorable background cyclonic vorticity through most of the year (results obtained from the NOAA Earth System Research Laboratory's Plotting and Analysis page-not shown). In cluster 3, especially, TCs are almost equally likely to form in any month from November to April. Cluster 1 in the western SIO peaks in January and is characterized by strong asymmetry, with a sharp increase from December to January (more than double the number of storms). Clusters 4 and 5 within the AR show a combined peak in February, though individually there are subtle differences: cluster 5, whose main genesis region around $135^{\circ} \mathrm{E}$ (just off the northern Australian coastline) has a notable dip in January, with more storms forming in December. Clusters 6 (eastern AR) and 7 (SPO) reveal more typical seasonality, much like cluster 4 in the AR. The differences in seasonality between clusters are the result of changes in the large-scale environmental factors associated with TC formation (e.g., SST, low-level vorticity, vertical wind shear), as many previous studies have shown for specific basins. For instance, McBride and Keenan (1982) found that $95 \%$ of TCs in the AR form in association with the monsoon shear line, which is situated over the northern Australia from December to March. In the SPO, TC formation has been shown to be closely related to the position and strength of the South Pacific Convergence Zone (SPCZ) (e.g., Revell and Goulter 1986; Vincent et al. 2009), which is most active from December to March and peaks around January (Meehl 1987). 
Fig. 4 The distribution of maximum intensity (kts) for each cluster. The median maximum intensity is indicated by the white circles, and the interquartile range by the thick black lines. The thin lines extend to 1.5 times the interquartile range. The widths of the plots represent the density distribution for a given intensity

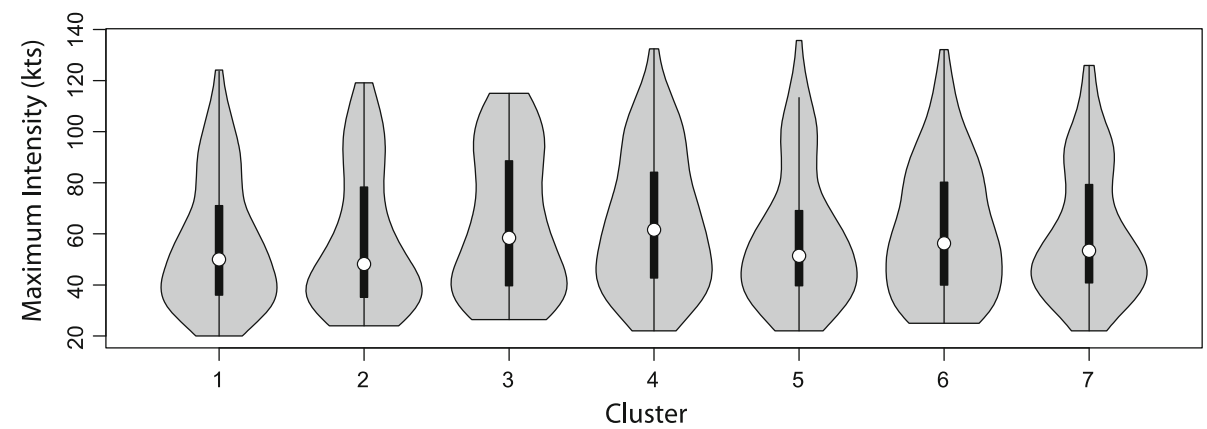

\subsection{Intensity}

TC intensity and its relationship with the large-scale environment, particularly pertaining to climate variability and change, is still not well understood and is a major area of ongoing research in the TC community. For instance, Kossin and Camargo (2009) showed that in the case of the North Atlantic, track variability is responsible for a significant part of the trend in the potential intensity of hurricanes in that basin in recent years. Recently, some effort has been made to document TC intensity trends in the Southern Hemisphere (e.g., Kossin et al. 2007; Harper et al. 2008; Hassim and Walsh 2008; Kuleshov et al. 2010; Callaghan and Power 2011) and we do not attempt to do so here. We focus rather on a comparison of the mean climatological characteristics of TC intensity in each cluster, using the TC seasons from 1981/1982 to 2007/2008.

Figure 4 shows the distribution of the TCs' maximum intensities for each cluster in the form of a violin plot (a combination of a box plot and a kernel density plot; Hintze and Nelson 1998). The highest median maximum intensities are found in the eastern SIO (cluster 3) and western AR (cluster 4), while many high-intensity TCs form in clusters 3, 4 and 6, as evidenced by the fat upper tails. Most clusters are heavily weighted toward the low-intensity rage, however cluster 7 in the SPO, and to some extent clusters 2 and 3 (SIO) and 5 (AR), indicate bimodal behavior with secondary peaks at higher intensities.

Total Accumulated Cyclone Energy (ACE), defined as the sum of the squares of the wind speed estimates at 6-hourly intervals over the period of interest (Bell et al. 2000), is shown in Fig. 5a. Traditionally, only wind speeds of greater than tropical storm intensity (i.e., at least $35 \mathrm{kts}$ ) are included in the calculation of ACE, however here we expand it to include all wind speeds in the IBTrACS data set. Highest total ACE is found over the SIO (cluster 3), with relatively small totals for clusters 4 and 5 near Australia. However, it is clear from the distributions of ACE per storm in Fig. 5b (compared with Fig. 5a) that the high total ACE in some clusters is due primarily to higher storm (a)
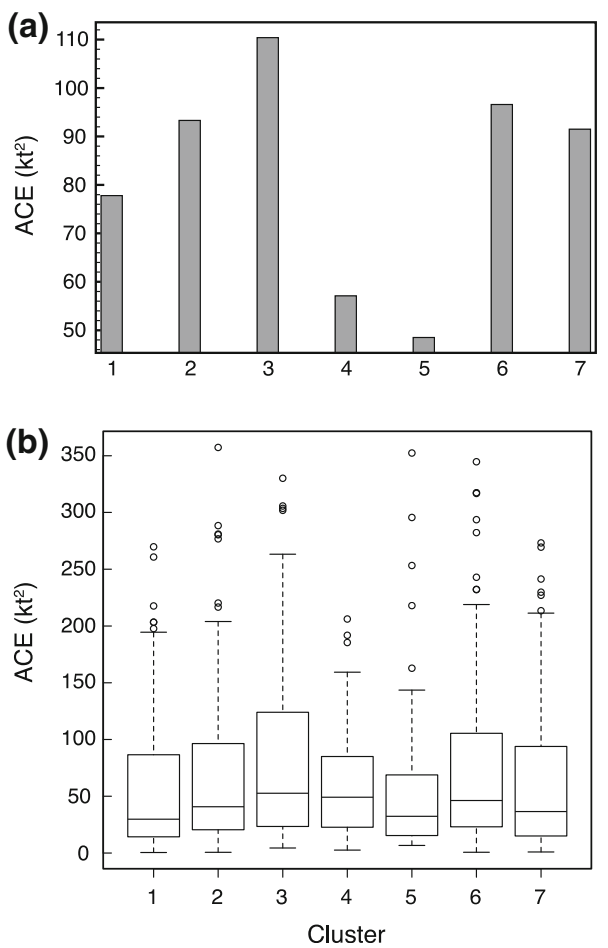

Fig. 5 a Total $\operatorname{ACE}\left(10^{6} \mathrm{kt}^{2}\right)$, and $\mathbf{b}$ distribution of $\operatorname{ACE}\left(10^{3} \mathrm{kt}^{2}\right)$ for each cluster

counts, as opposed to more intense storms. For instance, cluster 4 (AR) contains the second highest median ACE per storm despite it having the second lowest total ACE. Since ACE is an integrated quantity, it is important to take into account the total accumulated TC lifetime (i.e., TC Days) in each cluster. When this is accounted for, the highest ACE per day occurs in cluster 4 (AR), with a bell shaped distribution extending from west to east; i.e., cluster 1 to cluster 7 (not shown). As expected, the distributions of ACE in Fig. 5b are heavily weighted toward low values, with many outliers. The distributions are notably different from the maximum intensities (compare, for instance, clusters 4 between Figs. 4, 5), suggesting that TCs in particular clusters may attain high intensities but only for relatively short periods of time. 


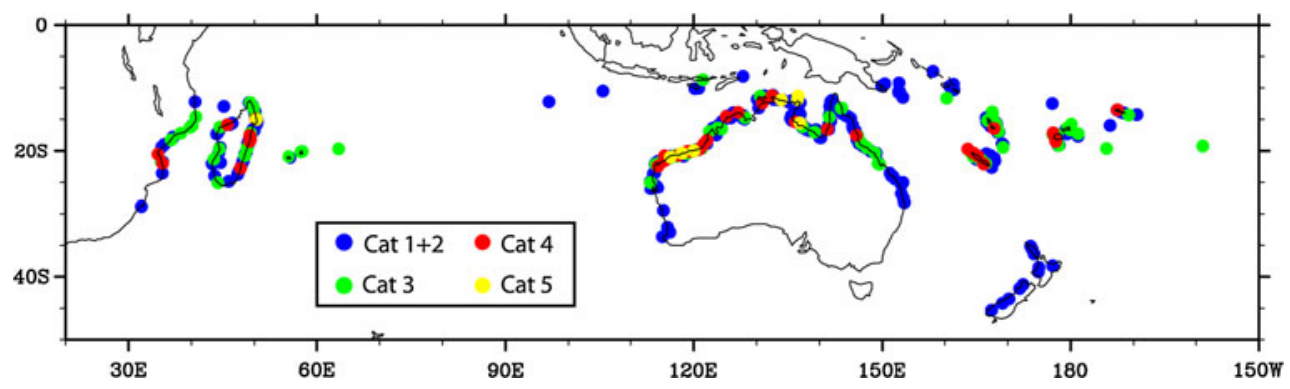

Fig. 6 Landfall locations of TCs for all clusters. The intensity at landfall is indicated by colors in the legend: blue for categories 1 and 2 , green for category 3 , red for category 4 and yellow for category 5 .

\subsection{Landfall}

Figure 6 shows TC landfall locations and intensities for all clusters from $1969 / 1970$ to $2007 / 2008$. Clearly, number of landfalls in the Southern Hemisphere is determined largely by a cluster's proximity to large landmasses, such as Australia, Madagascar, and east Africa. The number of direct hits to the islands of the SPO is relatively small owing to their small size, however they are most vulnerable to the impacts of TCs that pass close by, as will be shown in the next section. A high density of very intense landfalling TCs occurs over northern Australia, particularly the northwest Australian coastline that has the highest density of Category 4 and 5 (according to Australian classifications) TC landfalls. TCs that make landfall south of about $25^{\circ} \mathrm{S}$ in the Southern Hemisphere, such as New Zealand's west coast and southwestern Australia, tend to be relatively less intense with no severe landfalling TCs (i.e., those with sustained winds greater than $63 \mathrm{kt}$ ) since 1969/1970. This is in part because a large number of these TCs undergo extratropical transition prior to landfall, especially those in cluster 6 that impact New Zealand (Sinclair 2002). Clusters 1 (SIO), and 4-6 (AR) contain the most TC landfalls, with $65,64,80$, and 77 respectively (Fig. 7a). Many of these TCs make more than one landfall; especially cluster 5 over northern Australia, in which almost half of all TCs make multiple landfalls. Multiple landfalls are also common over the Coral Sea region in cluster 6, as they make landfall in many islands. The highest median intensities at landfall occur in clusters 3 (SIO), 4 (AR) and 7 (SPO), though clusters 3 and 7 are relatively small samples (Fig. 7b). TCs in cluster 5 on the other hand, while having the highest total number of landfalls, tend to be much weaker than their western Australian counterparts, aside from a few outliers of very high intensity (greater than $100 \mathrm{kts}$ ).

\subsection{Strike ACE}

The strict definition of landfall is somewhat limited as many TCs track close to land with significant impacts, yet
TC categories are according to the Australian Bureau of Meteorology's classification scheme (cat $1+2$ : 34-63 kt, cat 3: 64-85 kt, cat 4: 86-107 kt, cat 5: $>107 \mathrm{kt}$ )
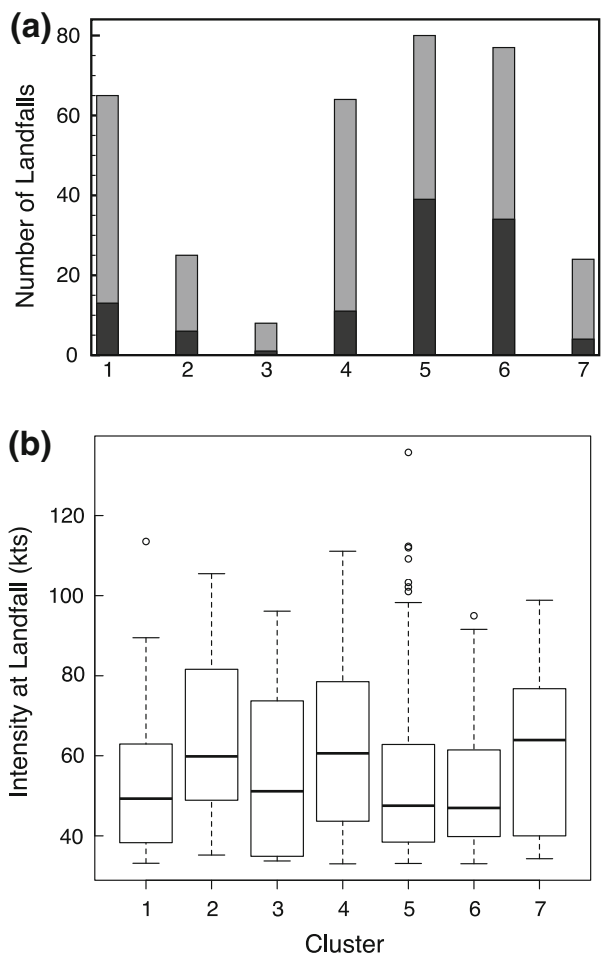

Fig. 7 a Number of TCs that made landfall at least once (gray bars) by cluster. The black bars show a subgroup of those TCs that made multiple landfalls. b The distribution of intensity at landfall

their centers may remain over ocean. To account for these events, we define a quantity "strike ACE", which is the ACE of all TCs whose centers pass within $50 \mathrm{~km}$ of land (including those that actually make landfall). Total strike ACE for all clusters, as well as the distribution per cluster, is shown in Fig. 8. The box plot in Fig. 8b is adjusted for large skewness according to the method proposed by Vanderviere and Huber (2004), to account for the large number of outliers. In contrast to the statistics of landfall, clusters 6 and 7 in the SPO contain the largest strike ACE, while clusters 1 and 4 are substantially reduced. Further, while only 24 TCs make landfall in cluster 7 , the number increases dramatically to 133 when TCs within $50 \mathrm{~km}$ of 

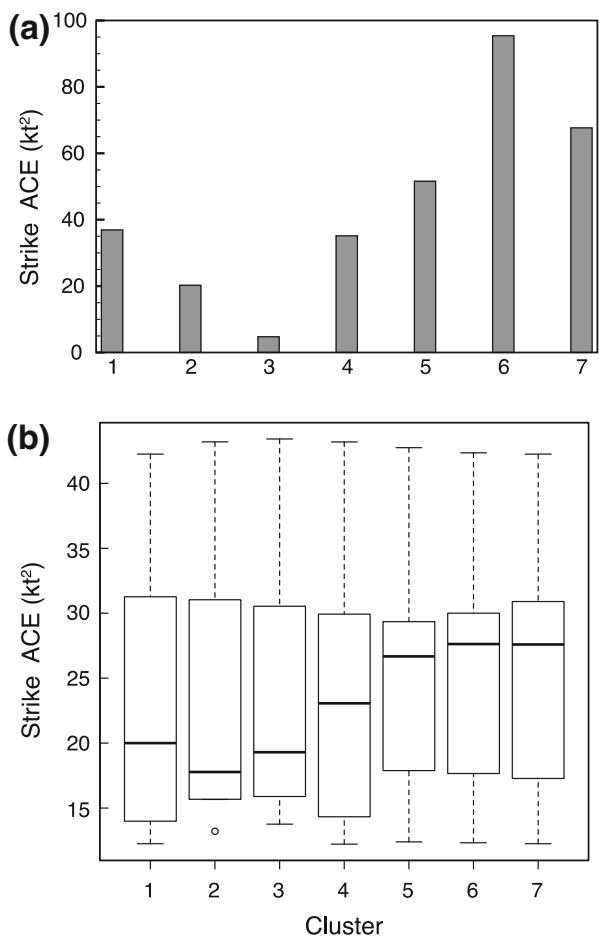

Fig. 8 a Total Strike ACE $\left(10^{5} \mathrm{kt}^{2}\right)$, and $\mathbf{b}$ the distribution of Strike ACE $\left(10^{2} \mathrm{kt}^{2}\right)$, adjusted for large right skewness

land are considered (Table 2). A similarly large increase occurs in cluster 6, from 77 (landfall) to 144 (within $50 \mathrm{~km}$ ). Thus, while the chance of a direct hit on a Pacific island is relatively small because of its size, we find that the SPO is most vulnerable to the effects of TCs as a whole.

Finally, turning to the AR, TCs in cluster 5 (northern AR) are substantially weaker at landfall than cluster 4 (western AR), yet in terms of strike ACE cluster 5 outweighs cluster 4 both in total and median values. The difference in medians can be explained by the fact that TCs in cluster 5 tend to track close to land for much longer periods of time ( $12 \mathrm{~h}$, vs. $7 \mathrm{~h}$ for cluster 4$)$ rather than being of greater intensity (Table 2). Strike ACE, therefore, appears to be a useful quantity for assessing the broader impacts of TCs, particularly to smaller island communities, and has obvious application to TC risk assessment techniques.
4.5 Composites of large-scale fields

\subsubsection{SST and OLR}

Composites of SST for each of the 7 clusters are shown in Fig. 9, with the regions of genesis superposed. It is well known that TCs can cool the upper ocean underneath them due to strong upwelling over short time scales (e.g. Bender and Ginis 2000). Therefore, we restrict our analysis to composites of the mean SST for the first complete week prior to TC genesis. The SST anomalies co-located with the regions of TC genesis (i.e. local SST anomalies) are generally positive and significant. However, these warm anomalies form part of a much larger warming signal across the Indo-Pacific region, rather than being constrained to the regions of TC formation. Cluster 7 in the SPO is unique in that the significant warm anomalies tend to be localized to the region where TC genesis occurs.

The SST anomalies associated with Cluster 7 in the SPO reveal a typical El Niño pattern (Rasmusson and Carpenter 1982), with significant warm anomalies over the eastern equatorial Pacific. Conversely, Clusters 3 (SIO) and 4 (AR) are associated with La Niña conditions, as indicated by the significant cool anomalies over a similar region.

All clusters are associated with significant negative OLR anomalies 2 days prior to genesis (Fig. 10), indicative of the well-known requirement for TC genesis of pre-existing regions of deep convection (e.g., Gray 1968). In the central $\mathrm{SIO}$, the anomalies are generally co-located with the KDE contours of genesis. Cluster 3 contains strong negative anomalies southwest of Indonesia around the main TC genesis region, and strong positive anomalies over the central Pacific, consistent with La Niña. Cluster 4 in the AR contains deep convection displaced to the north and east of TC genesis. Clusters 5 and 6 are associated with more disperse distributions of deep convection, with multiple maxima. Cluster 7 (SPO) also has strong negative OLR anomalies displaced to the north and east of its genesis region, consistent with the El Niño SST pattern shown in Fig. 9. A brief inspection of the composite JanMar OLR anomaly for El Niño years (as defined by NOAA's Oceanic Niño Index exceeding $+0.5^{\circ} \mathrm{C}$ ) reveals a

Table 2 Statistics showing differences between the total number of landfalls in each cluster, and the number of TCs that tracked within $50 \mathrm{~km}$ of land, as well as their respective median intensities

\begin{tabular}{lclllllc}
\hline & C1 & C2 & C3 & C4 & C5 & C6 & C7 \\
\hline Number of LF & 65 & 25 & 8 & 64 & 80 & 77 & 24 \\
Number of $\leq 50 \mathrm{~km}$ & 114 & 42 & 24 & 78 & 97 & 144 & 133 \\
Median Intensity at LF & 49.3 & 59.8 & 51.1 & 60.6 & 47.5 & 47 & 63.9 \\
Median max Intensity $\leq 50 \mathrm{~km}$ & 53.1 & 62.3 & 41.5 & 57.4 & 51.3 & 55.7 & 53.9 \\
Median lifetime (h) $\leq 50 \mathrm{~km}$ & 8 & 10 & 6 & 7 & 12 & 15 & 9 \\
\hline
\end{tabular}

The median lifetime (in hours) of TCs within $50 \mathrm{~km}$ of land is indicated on the bottom row 
C1

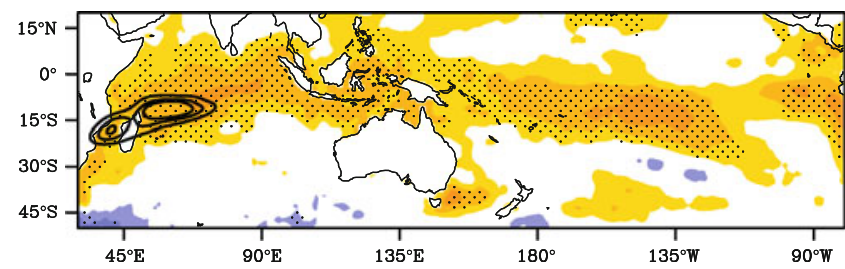

C3

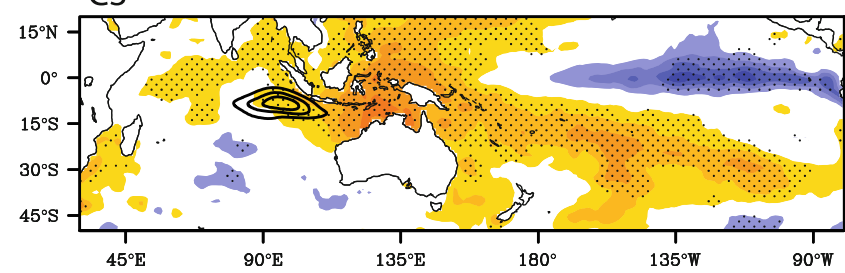

C5

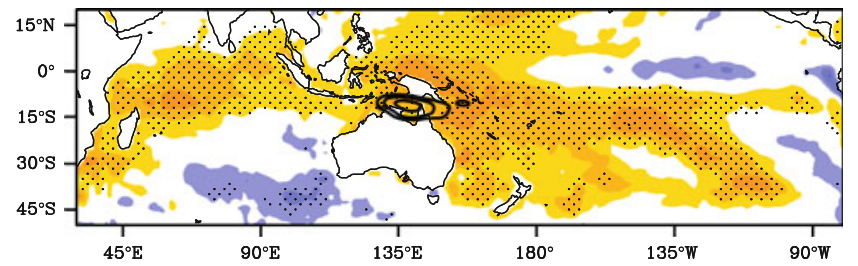

C2

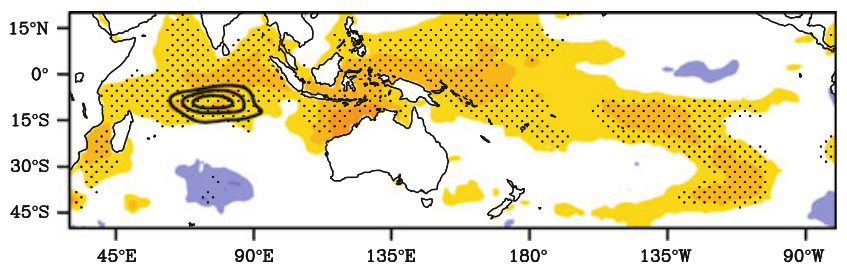

C4

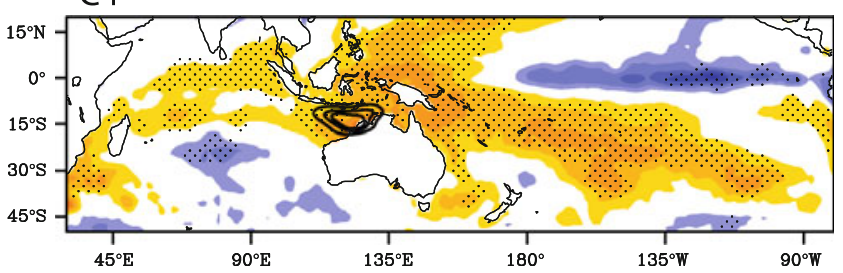

C6

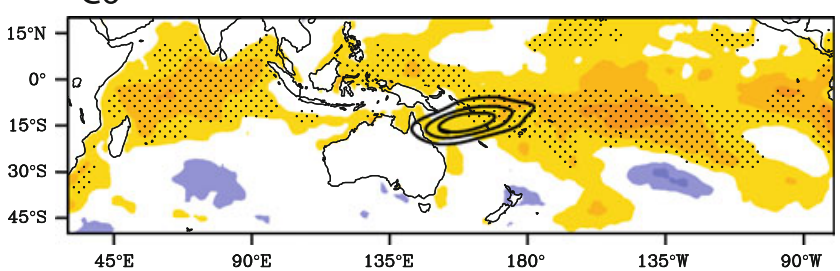

C7
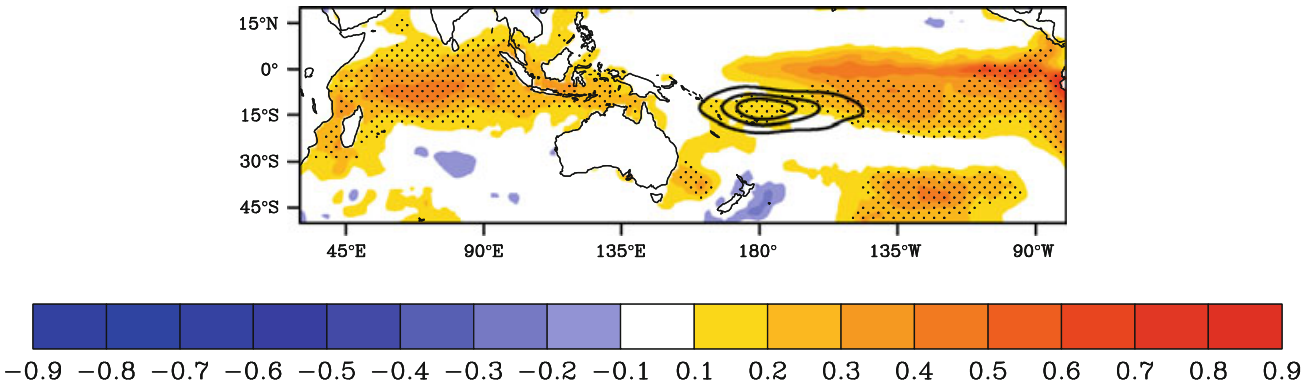

Fig. 9 Composites of weekly SST anomalies constructed using the first full week of SST data prior to TC genesis. The color bar gives the magnitude of the SST anomalies with units of degrees Celsius.

broad region of negative OLR anomaly from $10^{\circ} \mathrm{S}$ to the Equator and eastward of $160^{\circ} \mathrm{E}$, consistent with the OLR pattern for cluster 7 .

\subsubsection{Low-level winds, vorticity and vertical wind shear}

A common and robust feature of all clusters is the presence of strong $850-\mathrm{hPa}$ westerly wind anomalies immediately to the north of the TC genesis regions (Fig. 11). Six of the seven clusters are also characterized by strong easterly anomalies poleward of their genesis regions (the exception being cluster 1). During the core TC season, the climatological winds are westerly in the region extending from the equator to about $10^{\circ} \mathrm{S}$, and from the Indian Ocean to about the dateline. For cluster 7 in the SPO, the westerly anomalies centered near the dateline are superimposed on a transition zone from mean westerlies to mean easterlies,
Black contours show the 25, 50 and $75 \%$ KDEs of TC genesis in each cluster. Stippled regions indicate statistical significance of the anomalies using a moving-block bootstrap at the 5\% level

with the magnitude of the anomalies indicating a sign change (from easterly to westerly) east of the dateline, similar to the confluence region of genesis in the western North Pacific described in Ritchie and Holland (1999).

The low-level wind anomalies result in pools of significant cyclonic vorticity in the regions of TC genesis (Fig. 12), while 6 of the 7 clusters have significant anomalous anticyclonic vorticity located to the north of the genesis regions and over similar longitudes. These cyclonic/anticyclonic couplets are the result of the strong westerly zonal wind anomalies at $850 \mathrm{hPa}$ shown in Fig. 11 . Cluster 1 in the far western SIO is notably weaker than the other clusters, both in terms of vorticity and zonal wind, suggesting that this region is either inherently less predictable 2 days prior to genesis, or that TC genesis there is related to other large-scale processes apart from low-level wind and vorticity anomalies. It could also be that the TC 

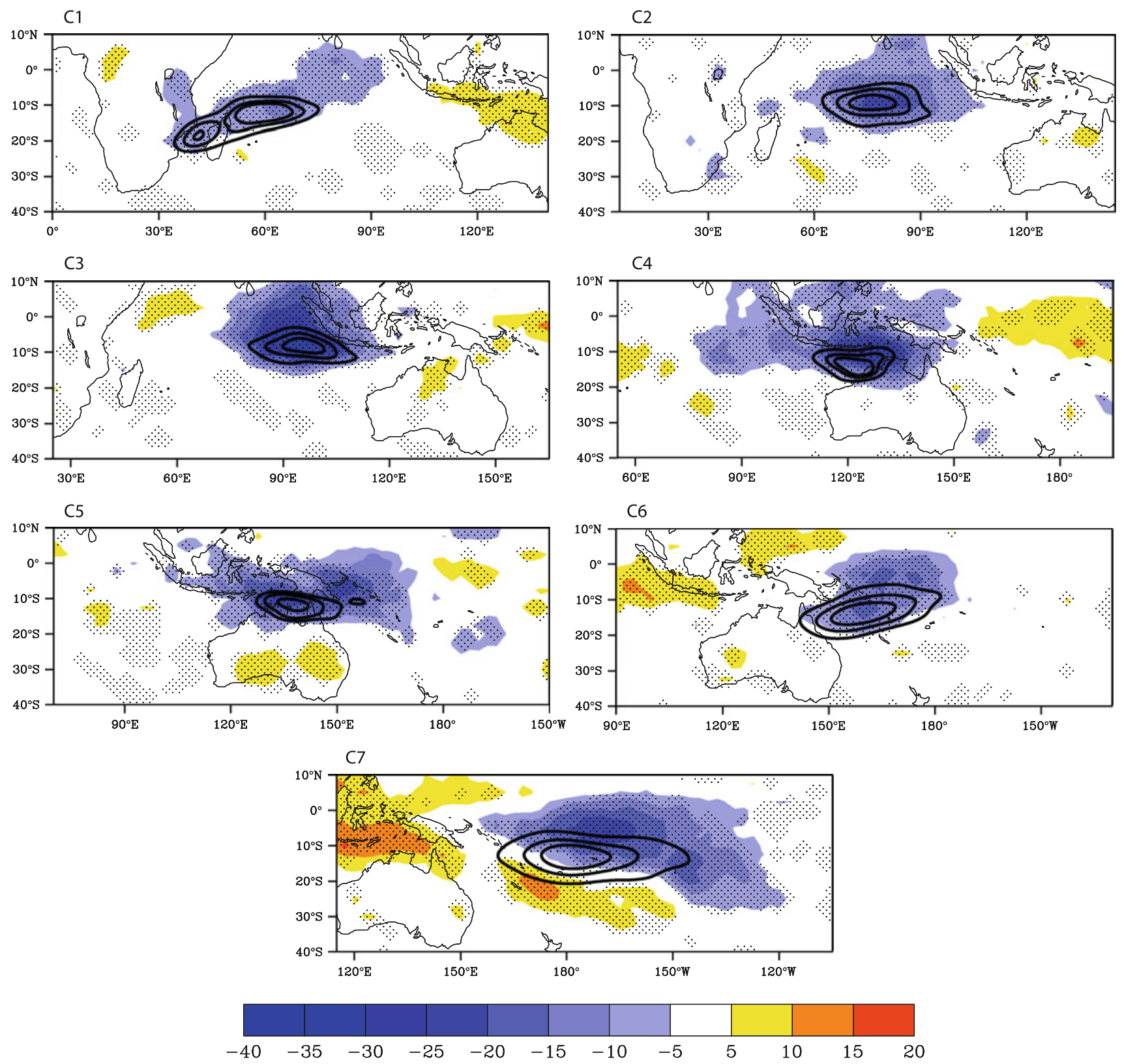

Fig. 10 Composites of daily OLR anomalies constructed using data 2 days prior to TC genesis. The color bar gives the magnitude of the OLR anomalies with units of $\mathrm{W} \mathrm{m}{ }^{-2}$. Black contours show the 25,50 and $75 \%$ KDEs of TC genesis in each cluster. Stippled regions indicate statistical significance of the anomalies using a moving-block bootstrap at the $5 \%$ level data is contaminated with systems that would not have been classified as TCs elsewhere. A strong and significant downward trend in the total number of TCs in cluster 1 (not shown) suggests a possible over-identification of systems from about 1970-1984. In general, areas of strong cyclonic vorticity are co-located with the regions of TC genesis, except for cluster 6 in the AR where the vorticity anomalies are displaced to the south and west with respect to genesis. The southward displacement is likely related to the presence of upstream diffluent upper-level troughs in the eastern Australian region, as has been discussed in more region-specific studies (e.g., Sinclair 2002).

Perturbations in magnitude of the deep-layer vertical wind shear appear to be relatively less important for TC genesis in the Southern Hemisphere. The genesis regions generally are situated between positive shear magnitude anomalies to the north and negative shear magnitude anomalies to the south (Fig. 13). For clusters 1-3 in the SIO, the negative shear anomalies are least important, and there is even some indication that genesis in cluster 2 is 

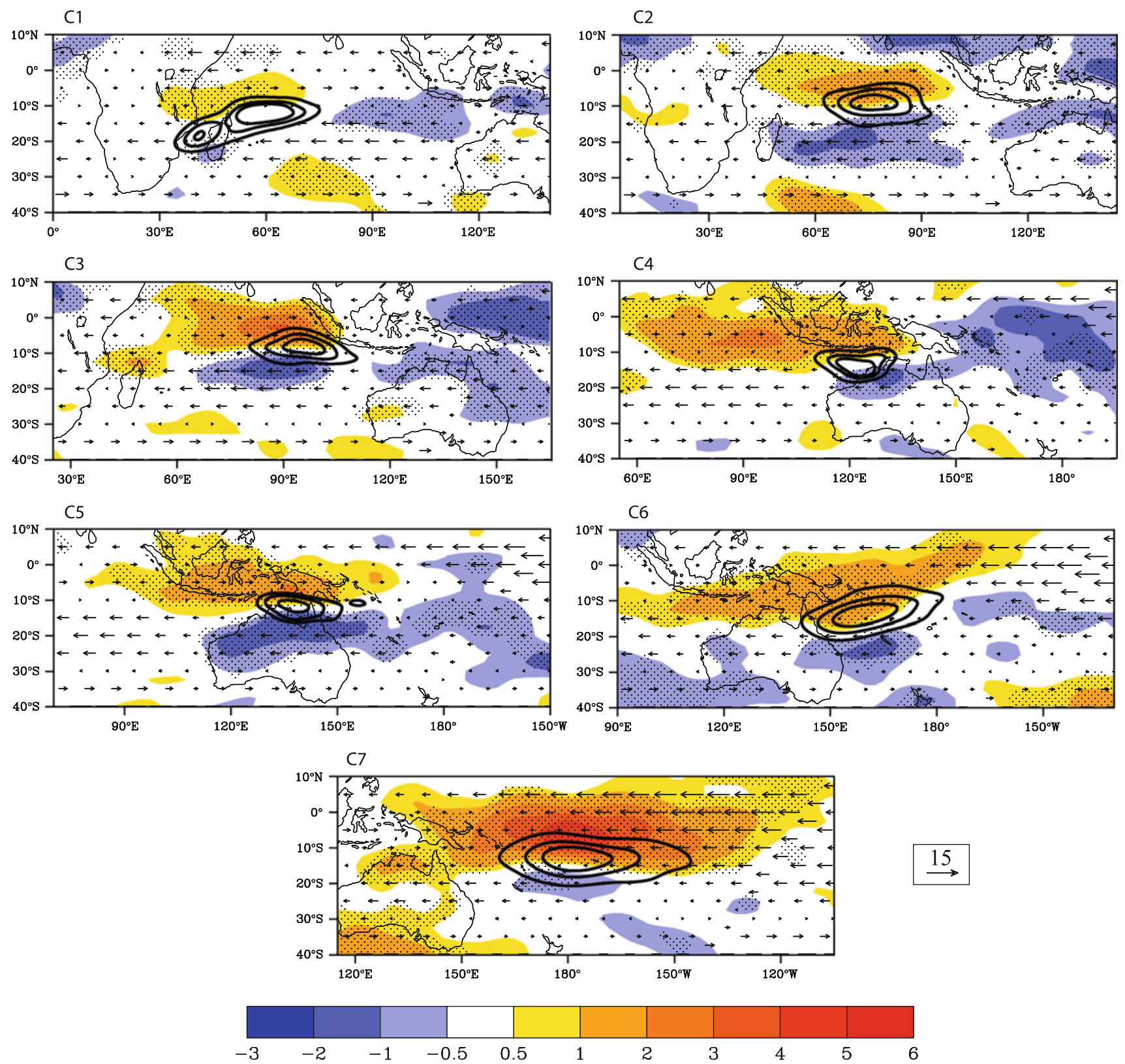

Fig. 11 As in Fig 10 but for 850-hPa zonal wind anomalies, with units of $\mathrm{m} \mathrm{s}^{-1}$. The arrows represent the climatological zonal winds. Sign and magnitude of the anomalies are indicated by the color bar

associated with higher than average (easterly) shear, as indicated by the significant positive anomalies around the central and northern genesis regions. Further, anomalous upper-level westerlies are found poleward of the genesis region in cluster 2 , resulting in higher shear magnitudes there. The significant negative shear anomalies in clusters 4 and 5 (AR) are generally poleward of the highest densities of genesis, and are the result of anomalously low upperlevel westerly flow (in contrast to cluster 2). The genesis in clusters 6 (eastern AR/Coral Sea) and 7 (SPO) appear to be most influenced by lower than average shear, where locally significant negative shear anomalies coincide with the central genesis contours. Climatologically, vertical wind shear tends to be lowest over the latitudes where most TCs form in the Southern Hemisphere-particularly over the monsoon shear line-(e.g., Dare and Davidson 2004), so while the mean vertical shear may be an important parameter for genesis, the perturbations about the mean appear to be relatively less important on the whole. This is in contrast with low-level zonal winds and vorticity, both of which appear to be insufficient in their climatological values to support the formation of TCs. 

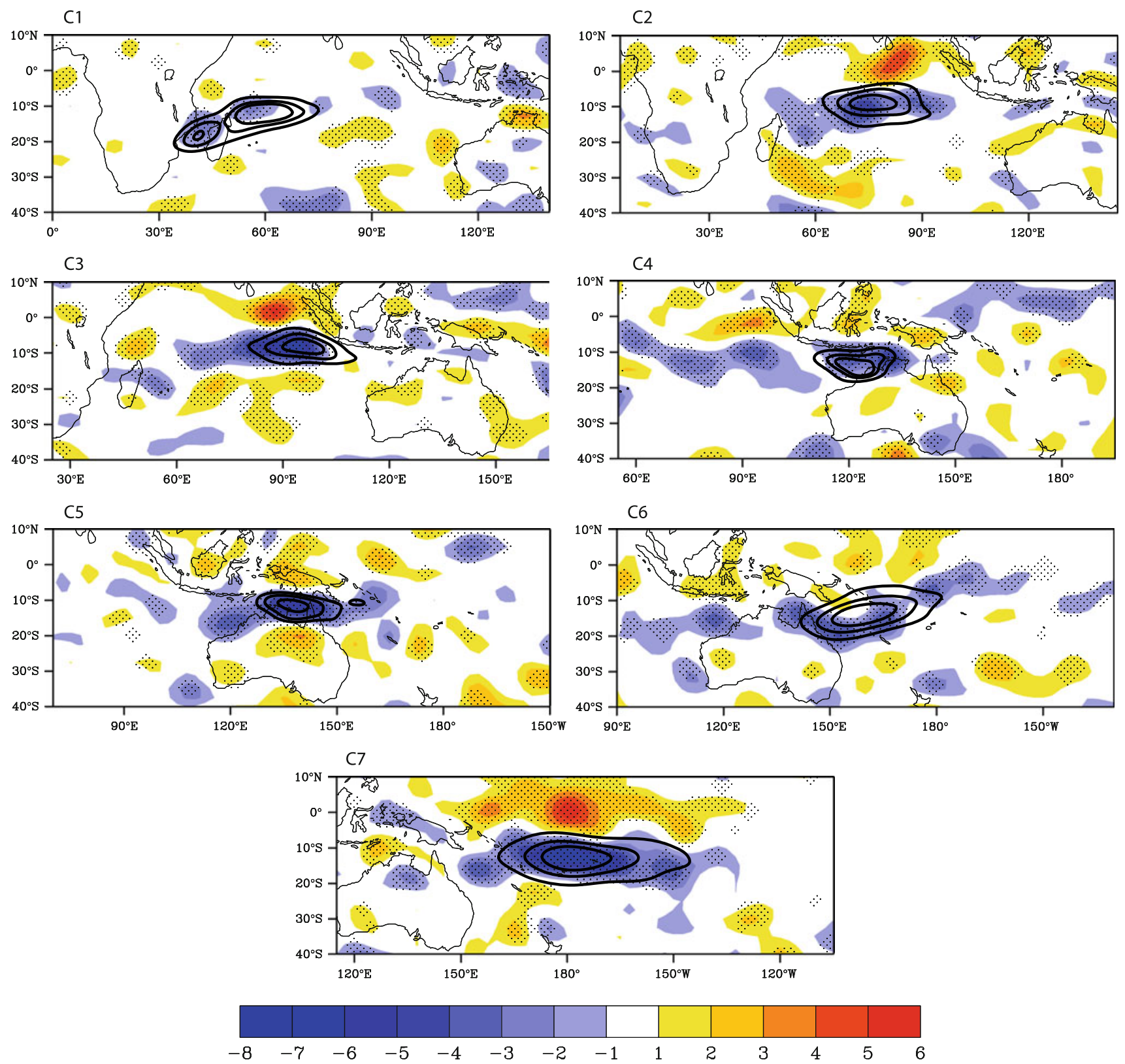

Fig. 12 As in Fig 10 but for 850-hPa relative vorticity anomalies, with units of $10^{6} \mathrm{~s}^{-1}$

\subsection{Relationship with ENSO}

The phase of ENSO has a well-known influence on the frequency of TCs in the Southern Hemisphere, particularly over the AR (e.g., Nicholls 1984; Kuleshov et al. 2008; Ramsay et al. 2008) and the SPO (Basher and Zheng 1995; Vincent et al. 2009; Chand and Walsh 2009). In this section, we investigate the effect of ENSO on both frequency and intensity of TCs in the individual clusters.

Figure 14 shows the frequency of TCs in each cluster stratified by ENSO phase. ENSO has a significant influence on TC frequency in 3 of the 7 clusters. Cluster 3 (SIO) and cluster 4 (AR) show enhanced (reduced) TC frequency during La Niña (El Niño), while cluster 7 (SPO) shows enhanced (reduced) TC frequency during El Niño (La Niña). These results are summarized in Table 3. La Niña has its strongest influence on TC genesis in cluster 3 over the eastern SIO. Unlike other studies on TC genesis and ENSO in the Southern Hemisphere (e.g., Sinclair 2002), we find no clear ENSO signal in TC genesis in the southwest Pacific region using the current configuration of clusters. However, we did find that when retaining more clusters ( $\mathrm{K}=10$ or more) a cluster emerged in the southwest Pacific, west of about $170^{\circ} \mathrm{E}$, whose genesis was enhanced (decreased) significantly during La Niña (El Niño). Sinclair (2002), in an analysis of South Pacific TC tracks, found 

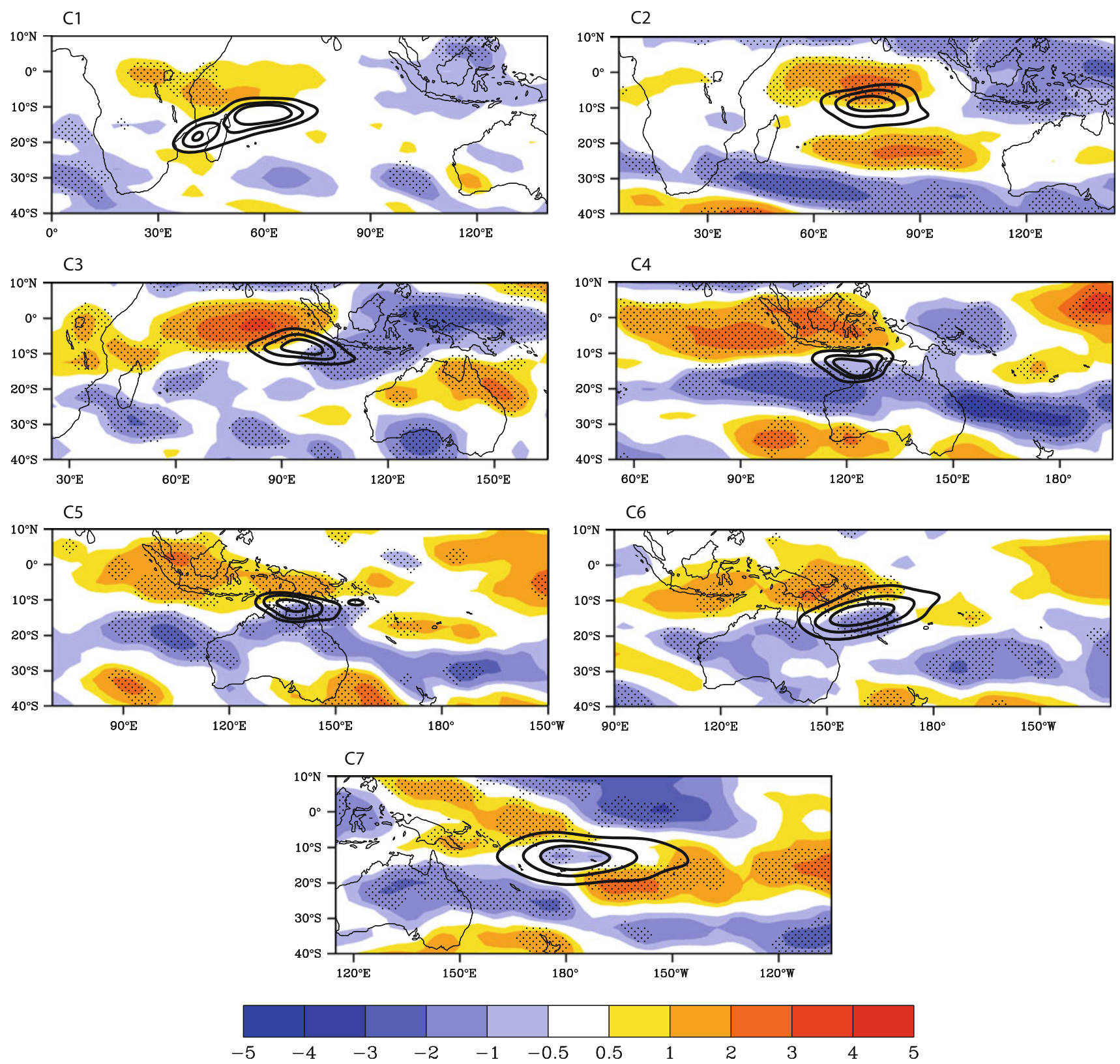

Fig. 13 As in Fig 10 but for 850-200-hPa vertical wind shear anomalies, with units of $\mathrm{m} \mathrm{s}^{-1}$

that La Niña conditions resulted in a westward shift of the mean trajectory with most storms occurring west of the dateline, similar to our results with $\mathrm{K}=10$ clusters (not shown). ENSO's modulating effect on TC genesis has been shown to change sign around $170^{\circ} \mathrm{E}$, with more (less) in $\mathrm{El}$ Niño east (west) of $170^{\circ} \mathrm{E}$ (e.g., Hastings 1990; Basher and Zheng 1995: Kuleshov and de Hoedt 2003; Chand and Walsh 2009). We find a similar sign change when we consider 10 clusters (not shown), though this is not true for the analysis using 7 clusters, presumably because cluster 6 in the eastern AR has a mixed response with respect to ENSO. Therefore, we conclude that the modulating effect of ENSO on TC genesis in the Southern Hemisphere is most robust and significant in the SIO east of about $80^{\circ} \mathrm{E}$ (clusters 3 and 4) and also in the SPO east of about $170^{\circ} \mathrm{E}$ (cluster 7).

Physically, the influence of ENSO on the frequency of TCs can be explained by changes in low-level winds and vorticity. Differences between El Niño and La Niña composites of $850-\mathrm{hPa}$ zonal winds and $850-\mathrm{hPa}$ relative vorticity are shown in Fig. 15. During El Niño events, westerly zonal winds on the equatorward side of the TC genesis regions are significantly enhanced, causing an associated increase in the low-level cyclonic vorticity where genesis occurs. The opposite is true during La Niña events. Over the eastern SIO (cluster 3), the effect of ENSO is reversed, with 


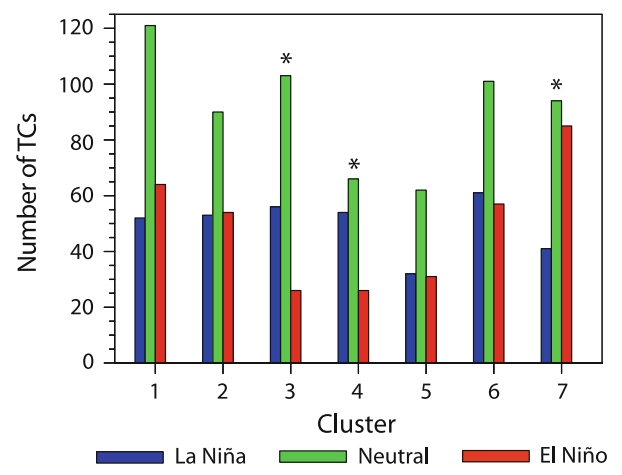

Fig. 14 The number of TCs in each cluster stratified by ENSO phase. The asterisks indicate significant differences between El Niño and La Niña at the $5 \%$ level according to the $\chi^{2}$ test

Table 3 The number of TCs in each cluster stratified by ENSO phase (El Niño, Neutral and La Niña), as well the total number

\begin{tabular}{lrrrrrrrr}
\hline & ALL & \multicolumn{1}{c}{ C1 } & \multicolumn{1}{c}{ C2 } & \multicolumn{1}{c}{ C3 } & C4 & C5 & C6 & C7 \\
\hline ALL & 1,329 & 237 & 197 & 185 & 146 & 125 & 219 & 220 \\
EN & 343 & 64 & 54 & $\mathbf{2 6}$ & $\mathbf{2 6}$ & 31 & 57 & $\mathbf{8 5}$ \\
NT & 637 & 121 & 90 & 103 & 66 & 62 & 101 & 94 \\
LN & 349 & 52 & 53 & $\mathbf{5 6}$ & $\mathbf{5 4}$ & 32 & 61 & $\mathbf{4 1}$
\end{tabular}

Bold font indicates significant differences at the $5 \%$ level based on a $\chi^{2}$ test

El Niño resulting in suppressed equatorial westerlies and cyclonic vorticity around $10^{\circ} \mathrm{S}$. The anomalous low-level circulation patterns associated with cluster 4 northwest of Australia are less clear (particularly vorticity), possibly because many storms form in close proximity to the Australian continent (e.g., McBride and Keenan 1982).

ENSO also modulates deep-layer vertical wind shear and mid-level relative humidity, though these appear to have little direct influence on TC genesis. The response of vertical wind shear to ENSO phase is mixed where TC genesis occurs, with the zero anomaly contour passing through the middle of the genesis KDEs. We find no significant difference in vertical shear between the two phases of ENSO (not shown). Similarly, no significant differences in mid-level relative humidity were found, with mixed signals around genesis regions (not shown). Therefore, we conclude that TC genesis in the clusters that are significantly influenced by ENSO is modulated primarily by changes in low-level zonal winds and relative vorticity.

Camargo et al. (2007c) used a Genesis Potential index to analyze the contribution of different environmental variables to the modulation of TCs by ENSO. The results of that study showed one could not point to one single environmental variable only to explain the ENSO-TC relationship in the Southern Hemisphere. The relative vorticity was shown there to be the main factor to the increase of TC genesis in the South Pacific around $10^{\circ} \mathrm{S}$ band, while the potential intensity was a main contributor to the modulation in the South Indian Ocean in the same latitudes. In contrast to the results here, in that analysis, the vertical shear and relative humidity were considered an important part of the ENSO-TC Southern Hemisphere modulation, as well as the potential intensity, which was not included in the analysis here.

While it has been shown that ENSO affects TC intensity in the western North Pacific (e.g., Camargo and Sobel 2005; Camargo et al. 2007b), much less is known about how ENSO may modulate intensity of TCs in the Southern Hemisphere. Table 4 shows the median ACE for each cluster stratified by ENSO phase. The largest difference occurs in cluster 6 (eastern AR/Coral Sea) with a substantial increase in ACE during El Niño, though the differences are not significant at the 5\% level.

Mean TC lifetime is also relatively unaffected by ENSO (Table 5), with the exception of cluster 7 (SPO), where TC lifetime is significantly shorter during El Niños compared to La Niñas (5.5 days vs. 6.7 days).

ENSO's influence on mean genesis position is described in Table 6. Cluster 2 in the SIO has its mean genesis position significantly displaced equatorward and westward (poleward and eastward) during El Niño (La Niña). Genesis in clusters 6 and 7 is shifted equatorward and eastward (poleward and westward) during El Niño (La Niña), consistent with other studies for the SPO region (e.g., Sinclair 2002; Basher and Zheng 1995; Chand and Walsh 2009). The shift in genesis is most pronounced in cluster 6 over the SPO. Further, the sign of the ENSO-genesis latitude relationship is consistent across clusters and sub-regions (i.e., the effect of El Niño/La Niña is always an equatorward/poleward shift). That ENSO has such a strong modulation on the longitude of genesis in clusters 2 and $6\left(5^{\circ}\right.$ $7^{\circ}$ ) suggests that these clusters are somewhere between the regions where forcing associated with ENSO is maximized.

\subsection{Relationship with MJO}

The modulation of TCs in the Southern Hemisphere by the MJO has received less attention than the modulation by ENSO. Liebmann et al. (1994) found that TC formation over the Indian Ocean is enhanced when the MJO is in its positive phase, mainly due to large-scale cyclonic vorticity anomalies southward of the MJO's convective envelope. A similar modulation was found by Bessafi and Wheeler (2006) and Ho et al. (2006) for the SIO, and for the Australian region by Hall et al. (2001) where the MJO-TC signal was found to be even stronger. Recently, Chand and Walsh (2010) showed a strong and significant MJO-TC relationship over the Fiji sub-region of the SPO, which was further enhanced during El Niño. The physical mechanisms associated with the MJO modulation of TCs vary 

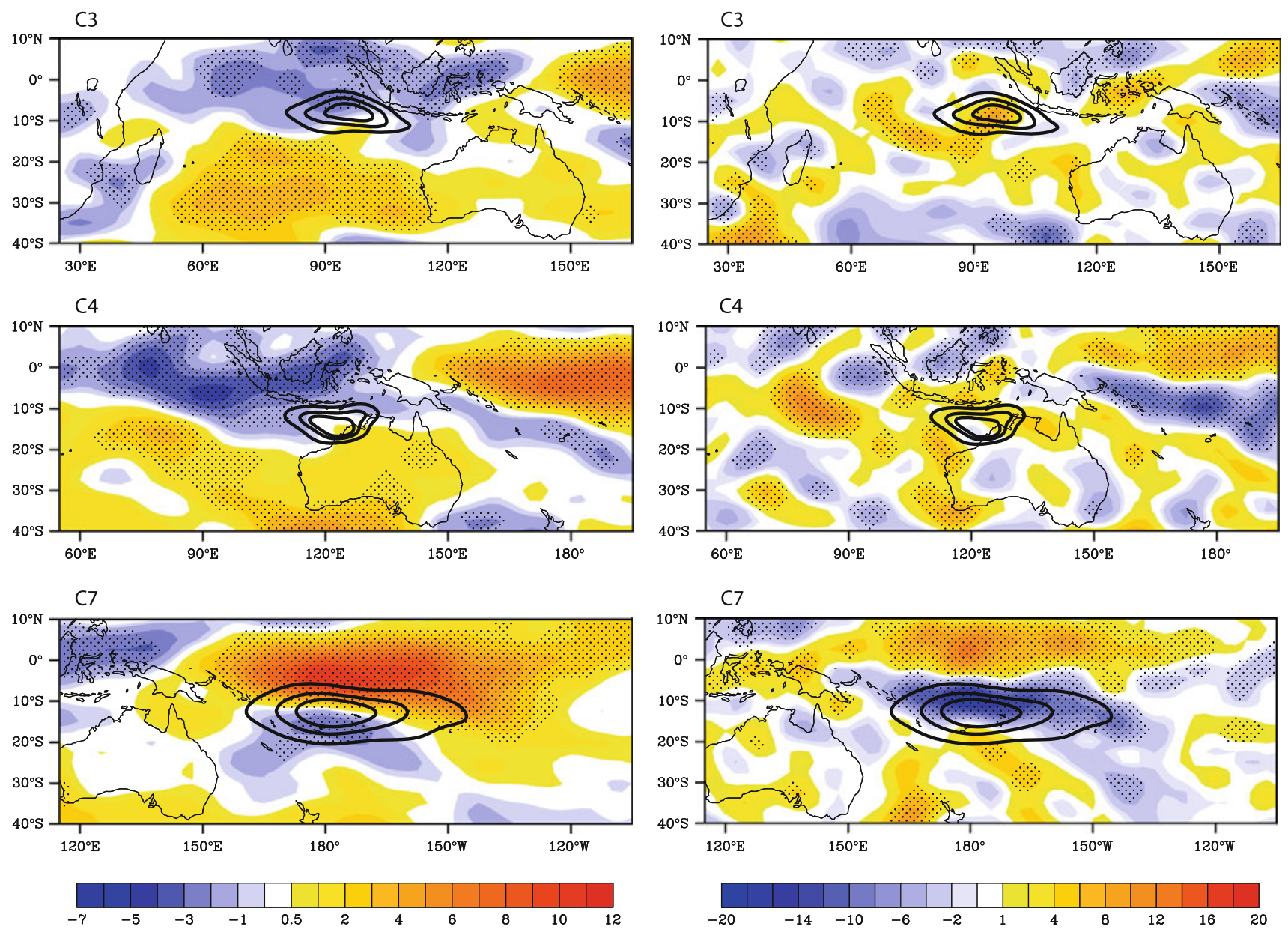

Fig. 15 Left panels Difference in zonal wind anomalies between El Niño and La Niña composites (El Niño minus La Niña) in units of $\mathrm{m} \mathrm{s}^{-1}$ for the 3 clusters whose genesis is significantly modulated by ENSO. Black contours show the 25, 50 and $75 \%$ KDE contours of TC

genesis. The sign and magnitude of the anomaly differences are shown by the color bar. Right panels Like the left panels, but for $850-\mathrm{hPa}$ relative vorticity anomalies

Table 4 As in Table 3, but for median ACE (with units of $10^{4} \mathrm{kt}^{2}$ )

\begin{tabular}{llllllll}
\hline & C1 & C2 & C3 & C4 & C5 & C6 & C7 \\
\hline ALL & 29.8 & 40.7 & 52.6 & 49.1 & 32.3 & 46.3 & 36.6 \\
EN & 28.8 & 40.4 & 55.4 & 53.9 & 23.5 & 63.5 & 38.8 \\
NT & 32.2 & 46.0 & 56.3 & 36.0 & 23.5 & 37.5 & 30.1 \\
LN & 28.5 & 37.1 & 43.6 & 61.9 & 40.8 & 46.5 & 36.6 \\
\hline
\end{tabular}

depending on region. In the context of a seasonal TC genesis parameter, Camargo et al. (2009) found that the primary contribution to the modulation of TC genesis was changes in mid-level relative humidity, followed by lowlevel absolute vorticity.

Here, we analyze the influence of the MJO on TC activity using both a real-time multivariate MJO index (Wheeler and Hendon 2004) and a second MJO index constructed using a 20-100 day band pass filter of daily OLR anomalies. The MJO-filtered OLR anomaly on $5^{\circ}$ by

Table 5 As in Table 3, but for mean TC lifetime (days)

\begin{tabular}{lccrrrrrr}
\hline & ALL & C1 & \multicolumn{1}{c}{ C2 } & C3 & C4 & C5 & C6 & C7 \\
\hline ALL & 8.0 & 7.3 & 9.3 & 10.0 & 7.2 & 7.8 & 8.7 & 6.1 \\
EN & 7.7 & 7.1 & 10.2 & 10.5 & 7.2 & 6.6 & 9.1 & $\mathbf{5 . 5}$ \\
NT & 8.1 & 7.5 & 8.8 & 9.8 & 7.1 & 8.2 & 8.5 & 6.5 \\
LN & 8.2 & 7.0 & 9.2 & 10.2 & 7.2 & 7.9 & 8.4 & $\mathbf{6 . 7}$ \\
\hline
\end{tabular}

Statistical significance is determined using a bootstrap test with 1,000 replications

$5^{\circ}$ grid described in Sect. 2 is used as a second index. Two questions we wish to address here are: (1) What is the relationship between MJO-phase and the frequency of TCs in each cluster, and (2) To what extent can the formation of TCs in a given cluster be attributed to the local convective signal associated with the MJO?

To address the first question, we stratify TC frequency in each cluster by the 8 phases of the MJO according to Wheeler and Hendon (2004), as shown in Fig. 16. To 
Table 6 As in Table 3, but for mean genesis position (longitude, latitude)

\begin{tabular}{lrrlcrrr}
\hline & \multicolumn{1}{l}{ C1 } & \multicolumn{1}{l}{ C2 } & \multicolumn{1}{c}{ C3 } & \multicolumn{1}{c}{ C4 } & \multicolumn{1}{c}{ C5 } & \multicolumn{1}{c}{ C6 } & \multicolumn{1}{c}{ C7 } \\
\hline ALL & 54.8 & 77.6 & 96.3 & 120.8 & 142.0 & 161.3 & 187.4 \\
& -15.1 & -10.1 & -9.2 & -13 & -11.9 & -13.1 & -14.6 \\
EN & 55.6 & $\mathbf{7 4 . 7}$ & 97.7 & 122.4 & 140.5 & $\mathbf{1 6 6 . 0}$ & $\mathbf{1 9 1 . 2}$ \\
& -14.4 & $\mathbf{- 9 . 5}$ & -9 & -13.2 & -11.5 & $-\mathbf{1 1 . 7}$ & $\mathbf{- 1 3 . 6}$ \\
NT & 55.1 & 77.8 & 95.5 & 119.9 & 141.4 & 160.3 & 184.1 \\
& -15.1 & -9.8 & -9 & -12.8 & -11.7 & -12.4 & -14.4 \\
LN & 53.1 & $\mathbf{8 0 . 1}$ & 97.1 & 121.0 & 144.7 & $\mathbf{1 5 8 . 7}$ & $\mathbf{1 8 7 . 0}$ \\
& -15.6 & $-\mathbf{1 1}$ & -9.7 & -13.2 & -12.6 & $-\mathbf{1 5 . 6}$ & $-\mathbf{1 7 . 2}$ \\
\hline
\end{tabular}

Statistical significance is determined using a bootstrap test with 1,000 replications

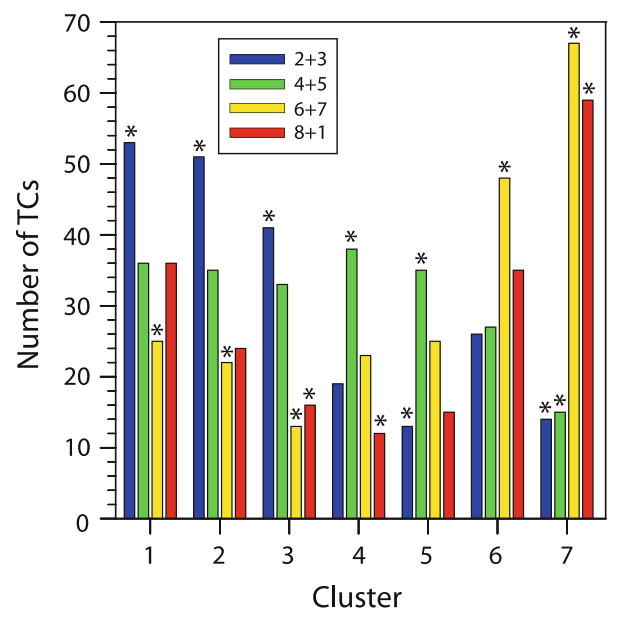

Fig. 16 Number of TCs stratified by the 4 combined phases $(8+1$, $2+3,4+5,6+7)$ of the Wheeler-Hendon MJO Index for each cluster. Phases that have a statistically significant (at 5\% level) modulation on TC frequency are indicated by the asterisks. Significance is determined using a Monte Carlo approach in which random MJO phases were assigned to TCs in each cluster and repeated 1,000 times

simplify analysis, the 8 phases are subdivided into 4 (Western Hemisphere: $8+1$, Indian Ocean: $2+3$, Maritime Continent: $4+5$, and Western Pacific $6+7$ ). Weak MJO events, defined as when the magnitude of the MJO index is less than unity, are excluded from the analysis though account for about $36 \%$ of all TCs.

Over the SIO, clusters 1-3 indicate significantly increased TC activity when the MJO is in phase $2+3$, consistent with enhanced OLR and low-level equatorial westerlies from about $60^{\circ} \mathrm{E}-100^{\circ} \mathrm{E}$. In addition, TC formation is suppressed in all SIO clusters during phase $6+7$ (Western Pacific). In the central and western AR (clusters 4 and 5), there are significantly more TCs when the MJO is in phase $4+5$ (Maritime Continent) and significantly less TC activity in phases $8+1$ (West. Hem. and Africa) and $2+3$ (Indian Ocean) in agreement with previous studies
Table 7 Total number of TCs in each cluster during the sub-period 1979-2008, as well as number of TCs forming associated with positive and negative MJO-related convective anomalies (defined locally using a $5^{\circ}$ by $5^{\circ}$ box), and their ratios

\begin{tabular}{lllllllll}
\hline & ALL & C1 & C2 & C3 & C4 & C5 & C6 & C7 \\
\hline $\begin{array}{c}\text { Total TC } \\
\text { count }\end{array}$ & 859 & 151 & 110 & 119 & 111 & 87 & 121 & 160 \\
$\begin{array}{c}\text { Positive } \\
\text { MJO }\end{array}$ & 259 & 33 & 32 & 45 & 34 & 31 & 38 & 46 \\
$\begin{array}{c}\text { Negative } \\
\text { MJO }\end{array}$ & 37 & 3 & 5 & 9 & 2 & 6 & 7 & 5 \\
$\begin{array}{c}\text { Ratio Pos/ } \\
\text { Neg }\end{array}$ & $7: 1$ & $11: 1$ & $6.4: 1$ & $5: 1$ & $17: 1$ & $5.2: 1$ & $5.4: 1$ & $9.2: 1$ \\
\hline
\end{tabular}

The ratios for all clusters are highly statistically significant at the 5\% level based on a $\chi^{2}$ test

(e.g., Leroy and Wheeler 2008). In the eastern AR over the Coral Sea, cluster 7 has increased TC activity during phase $6+7$. Finally, cluster 7 in the SPO has significantly more (less) TCs forming during phases $6+7$ and $8+1$ (phases $2+3,4+5$ ), and is the cluster most strongly modulated by the MJO according to the Wheeler-Hendon Index. As shown in Fig. 16, the number of TCs occurring during MJO phases $6+7(67)$ and $8+1$ (59) is more than three times those forming during phases $2+3$ (14) and $4+5$ (15). This result is generally consistent with Chand and Walsh (2010), who found a similar but more localized modulation of $\mathrm{TC}$ activity over the Fiji region $\left(170^{\circ} \mathrm{E}\right.$ to $\left.170^{\circ} \mathrm{W}\right)$.

To investigate the influence of the MJO on TC formation locally, we investigate the relationship between MJOfiltered OLR anomalies and TC genesis for the period 1979-2008 during the months November-April. Our findings are summarized in Table 7. Summing over the entire Southern Hemisphere, there were 859 total TCs, 259 of which formed in the positive MJO phase, and 37 of which formed in the negative phase. The conditional probability of TC genesis given a positive MJO locally is shown in Fig. 17. Several peaks occur, most notably over the central and western SIO, to the north and northwest of Australia, and over the SPO eastward of about $160^{\circ} \mathrm{E}$. The local modulation is strongest in cluster 4 (AR), with 34 TCs forming in the positive phase and only 2 in the negative phase (Table 7). Cluster 1 (SIO) and cluster 7 (SPO) also appear to be strongly affected by the MJO, with TC genesis about 10 times more likely to occur in the positive phase than the negative phase. It is interesting that the second and third strongest MJO-TC modulations occur over the far western SIO and central SPO despite the highest MJOfiltered OLR variance occurring over the maritime continent. The strong relationship in the SPO here is broadly consistent with Leroy and Wheeler (2008), who found 
(a) Probability of TC genesis $\left(\times 10^{-4}\right)$

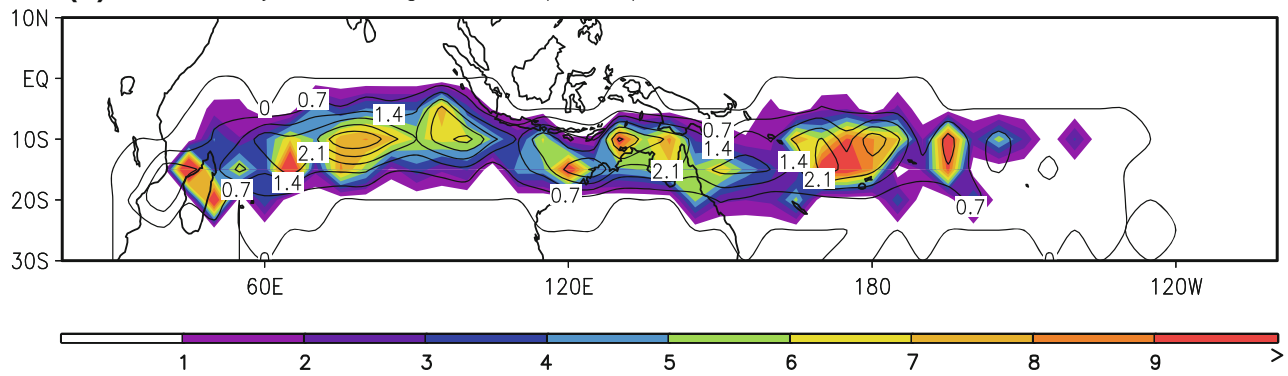

(b) Standard deviation of OLR anomaly $\left(\mathrm{W} \mathrm{m}^{-2}\right)$

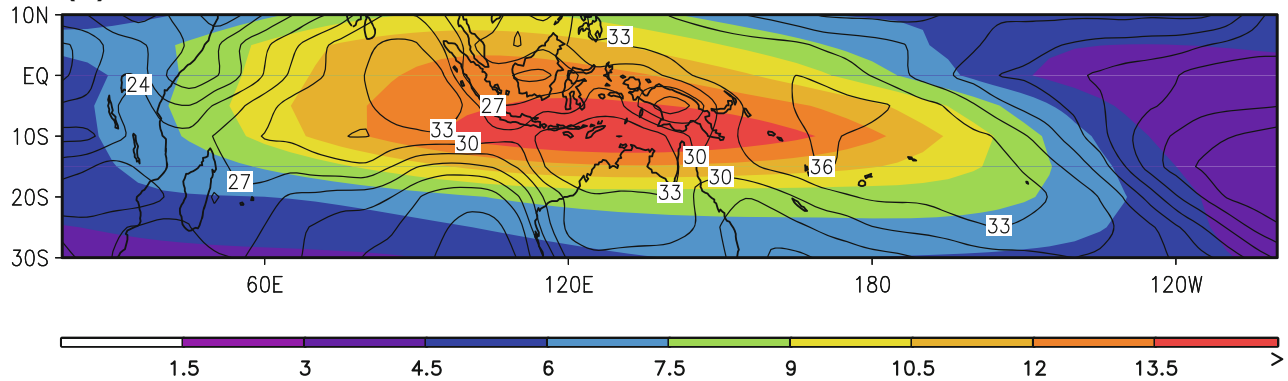

Fig. 17 a Climatological probability of TC genesis over the southern hemisphere (contours) and conditional probability of TC genesis with MJO-related active convection (shaded). b Standard deviation of total

strongest modulation of 8 to 1 in their Zone 4 (Pacific Ocean, east of the dateline), and with Chand and Walsh (2010) for the Fiji region $\left(170^{\circ} \mathrm{E}-170^{\circ} \mathrm{W}, 5^{\circ} \mathrm{S}-25^{\circ} \mathrm{S}\right)$. This suggests that the genesis mechanism for TCs over the AR region is different from that for TCs over the western SIO and central SPO.

\section{Summary and conclusions}

Cluster analysis was performed on 1,329 TC tracks in the Southern Hemisphere for the period July 1969-June 2008 using a finite-mixture model. The analysis shown here uses seven clusters, which were chosen based on several factors including statistical robustness, minimal internal error, and correlation with Niño 3.4 SST. The seven clusters were partitioned into three sub-regions: (1) the South Indian Ocean (SIO, clusters 1-3), (2) the Australian Region (AR, clusters 4-6), and (3) the South Pacific Ocean (SPO, cluster 7). Inspection of the regression curves shows clearly that TCs forming west (east) of about $140^{\circ} \mathrm{E}$ tend to move westward (eastward), and further that all clusters are characterized by relatively straight tracks with a notable lack of recurvature.

Distinct variability in seasonal cycle was noted between clusters. Clusters 2 and 3 in the SIO were found to have much flatter seasonal cycles compared to those clusters further east in the AR and SPO. In cluster 3, particularly, TCs appear equally as likely to form in any month from (contours) and MJO-filtered (shaded) OLR anomaly. Data obtained for November-April, 1979-2008 are used

November to April in association with favorable low-level cyclonic vorticity for a longer period of time relative to the other TC regions in the Southern Hemisphere.

In terms of intensity, the highest median maximum intensities were found in the western AR (cluster 4) and eastern SIO (cluster 3). Though the clusters were heavily weighted toward the lower intensities, some showed more bimodal behavior with a secondary peak in the higher intensity range, particularly cluster 7 in the SPO. Total ACE was found to be highest over the eastern SIO (cluster 3 ). When the number and duration of TCs were accounted for, the highest ACE per day was found in cluster 4 (western AR), with general decreasing trends in clusters both to the west and east.

Cluster 1 (SIO), and 4-6 (AR) were found to contain the most landfalling TCs (with 65, 64, 80, and 77 landfalls respectively), some of which made landfall multiple times. The highest density of severe landfalling TCs occurs on the northwest Australian coastline from TCs in clusters 4 and 5. We define a quantity strike ACE to account for TCs that track within $50 \mathrm{~km}$ of a coastline, similar to the definition of a hurricane strike. The highest strike ACE occurs over the SPO (cluster 6-7) because of the many small islands there.

Composites of weekly SST and daily large-scale atmospheric fields were constructed for each cluster. Large and significant SST anomalies (e.g., those associated with ENSO) were spread throughout the Indo-Pacific region, rather than being constrained spatially to a specific cluster. 
Anomalies of OLR, 850-hPa zonal wind, 850-hPa relative vorticity, and deep-layer vertical wind shear were also examined. A robust feature common to all clusters was the presence of strong 850 -hPa westerly wind anomalies on the equatorward side of the TC genesis regions. These westerly wind anomalies induced strong cyclonic vorticity anomalies that coincided spatially with TC genesis (occurring two days later). Deep-layer vertical wind shear and mid-level relative humidity were found to be less important.

ENSO has a strong modulating effect on the frequency of TCs in three clusters (clusters 3, 4 and 7), as well as on mean genesis position (clusters 2, 6 and 7). Significantly more (less) TCs form in cluster 7 (SPO) during El Niño (La Niña), while the opposite modulation occurs in clusters 3 and 4 (SIO and AR). ENSO affects TC frequency primarily by increasing the westerly component of the low-level winds on the equatorward side of the genesis regions, causing an associated increase in cyclonic vorticity. The deep-layer vertical wind shear and mid-level relative humidity were found to be less important. The relationship between ENSO and TC intensity was explored by considering median ACE stratified by ENSO phase. Cluster 6 in the Coral Sea region revealed a substantial increase in median ACE during El Niño, though the difference between El Niño and La Niña was not significant.

Finally, the MJO was found to have a strong modulation on frequency for all clusters. Generally, TC genesis in the $\mathrm{SIO}$ is enhanced (suppressed) during Indian Ocean phase (Western Pacific phase). The phase relationship is mixed in the AR, with enhanced (suppressed) activity when the MJO is over the Maritime Continent (Western Hemisphere, Indian Ocean) for clusters 4 and 5 to the west, and over Western Pacific for cluster 6 to the east. In cluster 7 over the SPO, genesis is enhanced (suppressed) when the MJO is located over the Western Pacific and Western Hemisphere (Indian Ocean and Maritime Continent). We constructed a secondary MJO-index to investigate the local influence of MJO-related convection on TC genesis. Using this local index, the strongest MJO-TC genesis signal was found to occur over the western $\mathrm{AR}$ in cluster 4, with a ratio of 17:1 between positive and negative MJO phases. Clusters 1 (western SIO) and 7 (SPO) were also strongly modulated by MJO, with ratios of about 10:1. Such strong modulation in the far Western Indian Ocean and central Pacific was somewhat surprising, given that that the peak in the MJO-filtered OLR variance occurs over the Maritime Continent, and remains the subject of future research.

Acknowledgments We are grateful to Matthew Wheeler for helpful discussions concerning the MJO. HAR acknowledges support by an appointment to the NASA Postdoctoral Program at the Goddard Institute for Space Studies, administered by Oak Ridge Associated Universities through a contract with NASA. SJC acknowledges support from NOAA Grant NA08OAR44320912. DK was supported by NASA Grant NNX09AK34G.

\section{References}

Barnston AG, Chelliah M, Goldenberg SB (1997) Documentation of a highly ENSO-related SST region in the equatorial Pacific. Atmos-Ocean 35:367-383

Basher RE, Zheng X (1995) Tropical cyclones in the southwest Pacific: spatial patterns and relationships to Southern Oscillation and sea surface temperature. J Clim 8:1249-1260

Bell GD et al (2000) The 1999 North Atlantic hurricane season: a climate perspective. State of the Climate in 1999. Bull Am Meteorol Soc 81:S1-S50

Bender MA, Ginis I (2000) Simulations of hurricane-ocean interaction using a high-resolution coupled model: effects on hurricane intensity. Mon Weather Rev 128:917-946

Bessafi M, Wheeler MC (2006) Modulation of south Indian Ocean tropical cyclones by the Madden-Julian oscillation and convectively coupled equatorial waves. Mon Weather Rev 134:638-656

Bowman AW, Azzalini A (1997) Applied smoothing techniques for data analysis: the kernel approach with S-plus illustrations. Oxford University Press, Oxford

Broadbridge LW, Hanstrum BN (1998) The relationship between tropical cyclones near Western Australia and the southern Oscillation index. Aust Meteorol Mag 47:183-189

Callaghan J, Power SB (2011) Variability and decline in the number of severe tropical cyclones making land-fall over eastern Australia since the late nineteenth century. Clim Dyn. Online first, doi:10.1007/s00382-010-0883-2

Camargo SJ, Sobel AH (2005) Western North Pacific tropical cyclone intensity and ENSO. J Clim 18:2996-3006

Camargo SJ, Robertson AW, Gaffney SJ, Smyth P, Ghil M (2007a) Cluster analysis of typhoon tracks. Part I: general properties. J Clim 20:3635-3653

Camargo SJ, Robertson AW, Gaffney SJ, Smyth P, Ghil M (2007b) Cluster analysis of typhoon tracks. Part II: large-scale circulation and ENSO. J Clim 20:3654-3676

Camargo SJ, Emanuel K, Sobel AH (2007c) Use of a genesis potential index to diagnose ENSO effects on tropical cyclone genesis. J Clim 20:4819-4834

Camargo SJ, Robertson AW, Barnston AG, Ghil M (2008) Clustering of eastern North Pacific tropical cyclone tracks: ENSO and MJO effects. Geochem Geophys Geosyst 9:Q06V05. doi: 10.1029/2007GC001861

Camargo SJ, Wheeler MC, Sobel AH (2009) Diagnosis of the MJO modulation of tropical cyclogenesis using an empirical index. J Atmos Sci 66:3061-3074

Camargo SJ, Sobel AH, Barnston AG, Klotzbach PJ (2010) The influence of natural climate variability on tropical cyclones and seasonal forecasts of tropical cyclone activity, Chapter 11. In: Chan JCL, Kepert JD (eds) Global perspectives on tropical cyclones, from science to mitigation, vol 4, 2nd edn. World Scientific Series on Earth System Science in Asia, Singapore, pp 325-360. ISBN 978-981-4293-47-1

Chand SS, Walsh KJE (2009) Tropical cyclone activity in the Fiji region: spatial patterns and relationship to large-scale circulation. J Clim 22:3877-3893

Chand SS, Walsh KJE (2010) The influence of the Madden-Julian oscillation on tropical cyclone activity in the Fiji region. J Clim 23:868-886

Dare RA, Davidson NE (2004) Characteristics of tropical cyclones in the Australian region. Mon Weather Rev 132:3049-3065 
Elsner JB (2003) Tracking hurricanes. Bull Am Meteorol Soc 84:353-356

Elsner JB, Liu KB (2003) Examining the ENSO-typhoon hypothesis. Clim Res 25:43-54

Evans JL, Allan RJ (1992) El Niño/Southern Oscillation modification to the structure of the monsoon and tropical cyclone activity in the Australasian region. Int J Climatol 12:611-623

Gaffney SJ (2004) Probabilistic curve-aligned clustering and prediction with regression mixture models. Ph.D. thesis, University of California, Irvine, $281 \mathrm{pp}$. Available online at http://www.ics. uci.edu/pub/sgaffney/outgoing/sgaffney_thesis.pdf

Gaffney SJ, Robertson AW, Smyth P, Camargo SJ, Ghil M (2007) Probabilistic clustering of extratropical cyclones using regression mixture models. Clim Dyn 29:423-440

Goddard L, Dilley M (2005) El Niño: catastrophe or opportunity? J Clim 18:651-655

Goebbert KH, Leslie LM (2010) Interannual variability of northwestern Australian tropical cyclones. J Clim 23:4538-4555

Gray WM (1968) Global view of the origin of tropical disturbances and storms. Mon Weather Rev 96:669-700

Hall JD, Matthews AJ, Karoly DJ (2001) The modulation of tropical cyclone activity in the Australian region by the Madden-Julian oscillation. Mon Weather Rev 129:2970-2982

Harper BA, Stroud SA, McCormack M, West S (2008) A review of historical tropical cyclone intensity in northwestern Australia and implications for climate change trend analysis. Aust Meteorol Mag 57:121-141

Harr PA, Elsberry RL (1995) Large-scale circulation variability over the tropical western North Pacific. Part I: spatial patterns and tropical cyclone characteristics. Mon Weather Rev 123:1225-1246

Hassim MEE, Walsh KJE (2008) Tropical cyclone trends in the Australian region. Geochem Geophys Geosys 9:Q07V07

Hastings PA (1990) Southern Oscillation influences on tropical cyclone activity in the Australian South-West Pacific region. Int J Climatol 10:291-298

Hintze JL, Nelson RD (1998) Violin plots: a box plot-density trace synergism. Am Stat 52:181-184

Ho C-H, Kim J-H, Jeong J-H, Kim H-S, Chen D (2006) Variation of tropical cyclone activity in the South Indian Ocean: El NiñoSouthern Oscillation and Madden-Julian Oscillation effects. J Geophys Res 111:D22101. doi:10.1029/2006JD007289

Holland GJ (1984) Tropical cyclone motion: a comparison of theory and observation. J Atmos Sci 41:68-75

Kalnay E et al (1996) The NCEP/NCAR 40-year reanalysis project. Bull Am Meteorol Soc 77:437-471

Kim H-S, Kim J-H, Ho C-H, Chu P-S (2011) Pattern classification of typhoon tracks using the fuzzy c-means clustering method. J Clim 24:448-508

Knapp KR, Kruk MC, Levinson DH, Diamond HJ, Neumann CJ (2010) The international best track archive for climate stewardship (IBTrACS): unifying tropical cyclone data. Bull Am Meteorol Soc 91:363-376

Kossin JP, Camargo SJ (2009) Hurricane track variability and secular potential intensity trends. Clim Change 9:329-337

Kossin JP, Knapp KR, Vimont DJ, Murnane RJ, Harper BA (2007) A globally consistent reanalysis of hurricane variability and trends. Geophys Res Lett 34:L04815

Kossin JP, Camargo SJ, Sitkowski M (2010) Climate modulation of North Atlantic hurricane tracks. J Clim 23:3057-3076

Kuleshov Y, de Hoedt G (2003) Tropical cyclone activity in the Southern Hemisphere. Bull Aust Meteorol Oceanogr Soc 16:135-137

Kuleshov Y, Qi L, Fawcett R, Jones D (2008) On tropical cyclone activity in the Southern Hemisphere: trends and the ENSO connection. Geophys Res Lett 35:L14S08. doi:10.1029/2007 GL032983
Kuleshov Y, Ming FC, Qi L, Choaibou I, Hoareau C, Roux F (2009) Tropical cyclone genesis in the southern hemisphere and its relationship with ENSO. Ann Geophys 27:2423-2538

Kuleshov Y, Fawcett R, Qi L, Trewin B, Jones D, McBride J, Ramsay $H$ (2010) Trends in tropical cyclones in the South Indian Ocean and the South Pacific Ocean. J Geophys Res 115:D01101. doi: 10.1029/2009JD012372

Künsch HR (1989) The jackknife and the bootstrap for general stationary observations. Ann Stat 17:1217-1241

Leroy A, Wheeler MC (2008) Statistical prediction of weekly tropical cyclone activity in the southern Hemisphere. Mon Weather Rev 136:1083-1103

Liebmann B, Smith CA (1996) Description of a complete (interpolated) outgoing longwave radiation dataset. Bull Am Meteorol Soc 77:1275-1277

Liebmann B, Hendon HH, Glick JD (1994) The relationship between tropical cyclones of the western Pacific and Indian oceans and the Madden-Julian oscillation. J Meteorol Soc Jpn 72:401-412

Liu RY, Singh K (1992) Moving blocks bootstrap captures weak dependence. In: Lepage R, Billard L (eds) Exploring the limits of bootstrap. Wiley, New York, pp 225-248

McBride JL, Keenan TD (1982) Climatology of tropical cyclone genesis in the Australian region. J Climatol 2:13-33

Meehl GA (1987) The annual cycle and interannual variability in the tropical Indian and Pacific Ocean regions. Mon Weather Rev $115: 27-50$

Nakamura J, Lall U, Kushnir Y, Camargo SJ (2009) Classifying North Atlantic tropical cyclone tracks by their mass moments. J Clim 22:5481-5494

Neumann CJ (1993) Global overview. In: Holland G (ed) Global guide to tropical cyclone forecasting, vol 1. WMO, Geneva, pp 1-56

Nicholls N (1979) A possible method for predicting seasonal tropical cyclone activity in the Australian region. Mon Weather Rev 107:1221-1224

Nicholls N (1984) The southern oscillation, sea-surface temperature, and internannual fluctuations in Australian tropical cyclone activity. J Climatol 4:661-670

Nicholls N (1985) Predictability of interannual variations in Australian seasonal tropical cyclone activity. Mon Weather Rev 113:1144-1149

Nicholls N, Landsea CW, Gill J (1998) Recent trends in Australian tropical cyclone activity. Meteorol Atmos Phys 65:197-205

Pezza AB, Simmonds I (2008) Large-scale factors in tropical and extratropical cyclone transition and extreme weather events. Ann NY Acad Sci 1146:189-211. doi:10.1196/annals.1446.005

Philander SGH, Gu D, Halpern D, Lambert G, Lau N-C, Li T, Pacanowski RC (1996) Why the ITCZ is mostly north of the equator. J Clim 9:2958-2972

Ramsay HA, Leslie LM, Lamb PJ, Richman MB, Leplastrier M (2008) Interannual variability of tropical cyclones in the Australian region: role of large-scale environment. J Clim 21:1083-1103

Rasmusson EM, Carpenter TH (1982) Variations in tropical sea surface temperature and surface wind fields associated with the Southern Oscillation/El Niño. Mon Weather Rev 110:354-384

Revell CG, Goulter SW (1986) South Pacific tropical cyclones and the Southern Oscillation. Mon Weather Rev 114:1138-1145

Reynolds RW, Rayner NA, Smith TM, Stokes DC, Wang W (2002) An Improved In Situ and Satellite SST Analysis for Climate. J Clim 15:1609-1625

Ritchie EA, Holland GJ (1999) Large-scale patterns associated with tropical cyclogenesis in the western Pacific. Mon Weather Rev 127:2027-2043

Sinclair MR (2002) Extratropical transition of Southwest Pacific tropical cyclones. Part I: climatology and mean structure changes. Mon Weather Rev 130:590-609 
Solow A, Nichols N (1990) The relationship between the Southern Oscillation and tropical cyclone frequency in the Australian region. J Clim 3:1097-1101

Vanderviere E, Huber M (2004) An adjusted boxplot for skewed distributions. In: Antoch J (ed) COMPSTAT 2004, proceedings in computational statistics. Springer, Heidelberg, pp 1933-1940

Vincent EM et al (2009) Interannual variability of the South Pacific Convergence Zone and implications for tropical cyclone genesis. Clim Dyn. doi:10.1007/s0038200907163
Waliser DE, Gautier C (1993) A satellite-derived climatology of the ITCZ. J Clim 6:2162-2174

Wheeler M, Hendon HH (2004) An all-season real-time multivariate MJO index: development of an index for monitoring and prediction. Mon Weather Rev 132:1917-1932

Wheeler M, Kiladis GN (1999) Convectively coupled equatorial waves: analysis of clouds and temperature in the wavenumberfrequency domain. J Atmos Sci 56:374-399 